University of San Diego

Digital USD

2013-02-01

\title{
Relationship of Internet-Delivered Mantram Repetition Program to Burnout, Stress of Conscience, Spiritual Wellbeing, and Mindfulness in Healthcare Workers
}

Sheryl Leary PhD

University of San Diego

Follow this and additional works at: https://digital.sandiego.edu/dissertations

Part of the Nursing Commons

\section{Digital USD Citation}

Leary, Sheryl PhD, "Relationship of Internet-Delivered Mantram Repetition Program to Burnout, Stress of Conscience, Spiritual Wellbeing, and Mindfulness in Healthcare Workers" (2013). Dissertations. 439. https://digital.sandiego.edu/dissertations/439 Digital USD. It has been accepted for inclusion in Dissertations by an authorized administrator of Digital USD. For more information, please contact digital@sandiego.edu. 
UNIVERSITY OF SAN DIEGO

Hahn School of Nursing and Health Science

DOCTOR OF PHILOSOPHY IN NURSING

RELATIONSHIP OF INTERNET-DELIVERED MANTRAM REPETITION

PROGRAM TO BURNOUT, STRESS OF CONSCIENCE, SPIRITUAL WELLBEING, AND MINDFULNESS IN HEALTHCARE WORKERS

\author{
By \\ Sheryl Leary \\ A dissertation presented to the \\ FACULTY OF THE HAHN SCHOOL OF NURSING AND HEALTH SCIENCE \\ UNIVERSITY OF SAN DIEGO \\ In partial fulfillment of the \\ requirements for the degree \\ DOCTOR OF PHILOSOPHY IN NURSING
}

February 2013

Dissertation Committee

Jane M. Georges, PhD, RN, Chairperson

Linda Urden, DNSc, RN, CNS, NE-BC, FAAN, Committee Member

Jill Bormann, $\mathrm{PhD}, \mathrm{RN}$, Committee Member 


\begin{abstract}
This study evaluated the effect of the Mantram Repetition Program (MRP), an internetdelivered stress management course on burnout, stress of conscience, spiritual wellbeing, and mindfulness on a self-selected group of healthcare workers (HCWs). A quasiexperimental repeated measures design was used. Participants enrolled in a six-session MRP delivered over three months and completed baseline, post-course, and three-month post-course assessments. Measurement tools included the Maslach Burnout InventoryGeneral Survey (MBI-GS), the Stress of Conscience Questionnaire (SCQ), the Functional Assessment of Chronic Illness Therapy Spiritual Wellbeing Scale (FACIT-12), and the Mindfulness Awareness Attention Scale (MAAS).
\end{abstract}

Statistically significant effects of the MRP showed a decrease in the MBI-GS exhaustion subscale across the three time-points $[F(2,76)=3.93, p=.039]$ and a quadratic effect for professional efficacy subscale showing an initial increase followed by a decrease $[F(1,38)=6.54, p<.02]$. Stress of Conscience internal demand subscale had a quadratic effect $[F(1,34)=5.23, p<.03]$ and external demand subscale had a linear effect over time showing improvement post-course $[\mathrm{F}(1,34)=4.71, \mathrm{p}<.03]$. There was a statistically significant effect increasing the total FACIT-SP scores across the three timepoints $[F(2,37)=11.76, p<001)$ and a statistically significant effect in the total MAAS scores across the three time-points $[F(2,33)=18.19, \mathrm{p}<000)]$.

According to these results, the MRP program was effective in reducing exhaustion and improving professional efficacy, elements of burnout, stress of conscience, spiritual wellbeing, and mindfulness in HCWs. MRP may be of interest to those seeking innovative, portable methods to improve psychological wellbeing among HCWs. 
THIS PAGE INTENTIONALLY LEFT BLANK. 


\section{Dedication}

This dissertation is dedicated my soul mate and husband, Pat, with my deepest love and appreciation for your infinite encouragement and support in my professional endeavors.

To my sons, Chris and Jason: I am grateful for your love, understanding, and patience; I hope you are proud of me. 


\section{Acknowledgments}

This dissertation was only possible through God, my Shepherd and my All. I express my respect and appreciation to my entire dissertation committee. Thanks to my research mentor, Dr. Jill Bormann, for being the perfect role model and sharing her research and passion for Mantram Repetition with me and for paving the way for the wonderful opportunities that arose both professionally and personally. I am also pleased to acknowledge my committee chair, Dr. Jane Georges, for her nonjudgmental and wise counsel and her constant reassurance and gentle encouragement. I am grateful to Dr. Linda Urden for her dedication and passion to the nursing profession, and to Dr. Tom Smith, principal statistician, for his patience, guidance, and expertise.

Thanks also to Gracie for lending a paw, purr, and presence during the immeasurable hours of writing, and to my family, friends, and colleagues for their prayers, companionship, laughter, and understanding. 


\section{TABLE OF CONTENTS}

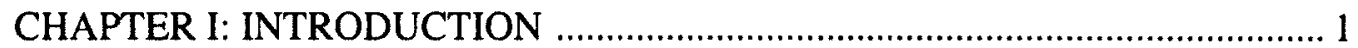

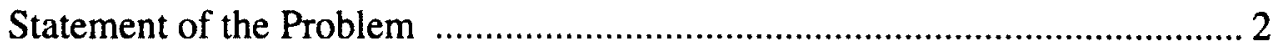

Background and Significance ……………................................................. 4

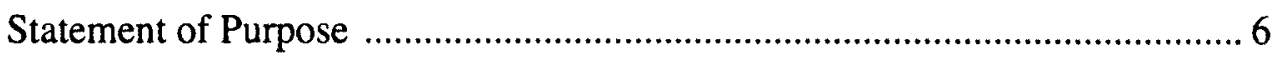

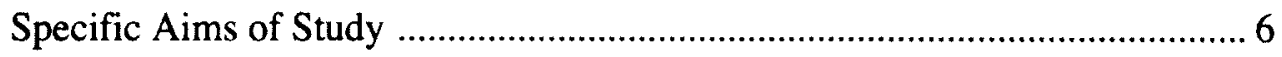

CHAPTER II: REVIEW OF THE LITERATURE …………........................... 9

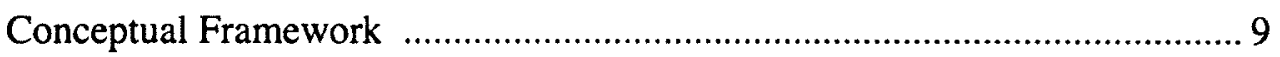

Theoretical Definitions .................................................................................. 11

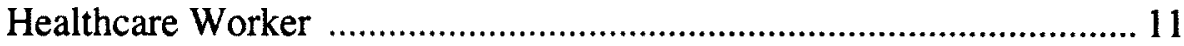

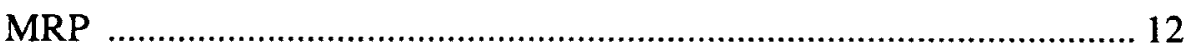

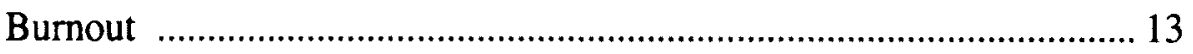

Stress of Conscience ………………………………………….... 13

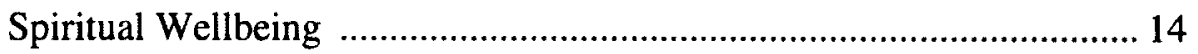

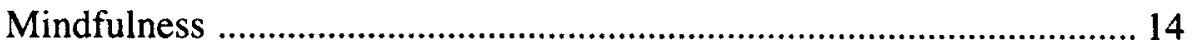

Principle Literature Review ........................................................................ 14

Self-Initiated Interventions for Burnout ……………………………..... 15

Mantram Repetition Program ……………………………………....... 21

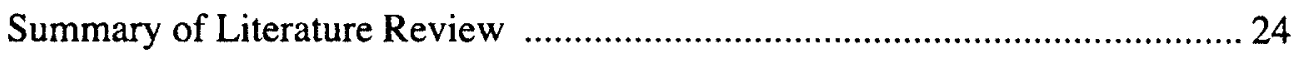

Importance to the Advancement of Knowledge ……………………............... 25 


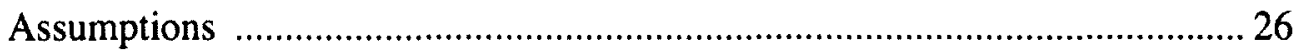

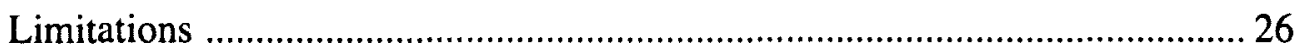

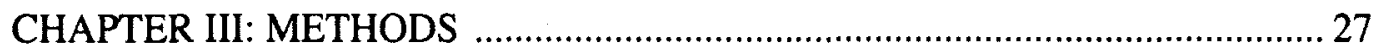

Specific Aims and Research Questions ...................................................... 27

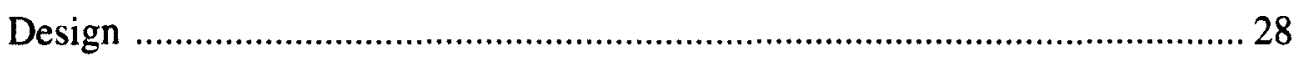

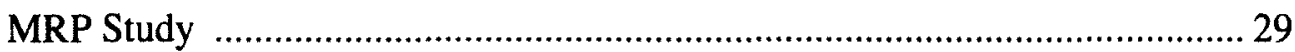

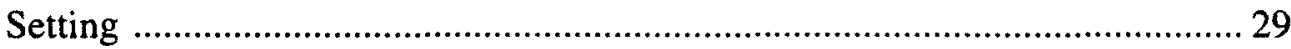

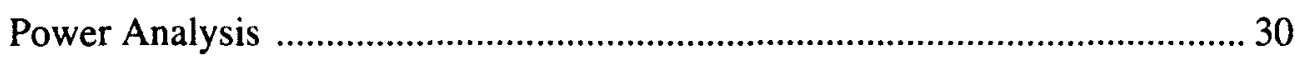

Protection of Human Subjects ................................................................ 30

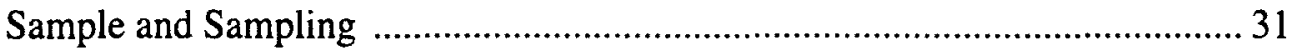

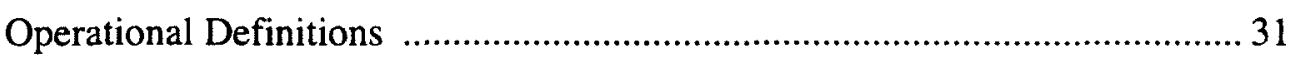

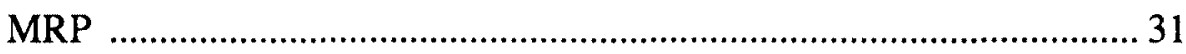

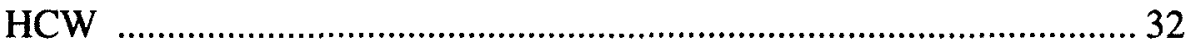

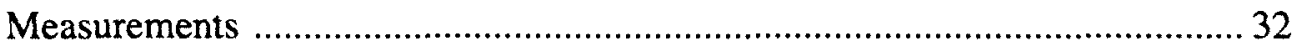

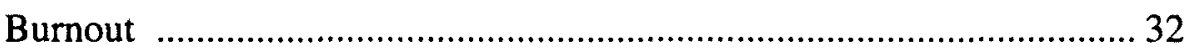

Stress of Conscience ...................................................................... 33

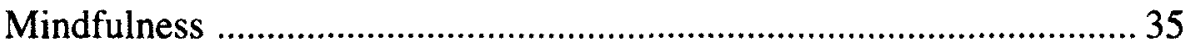

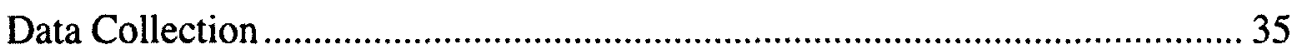

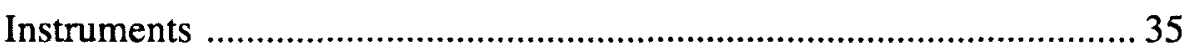

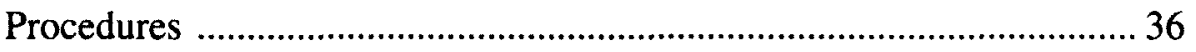




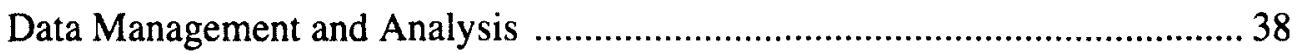

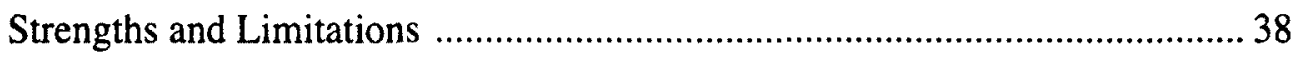

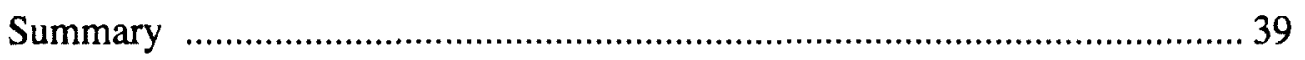

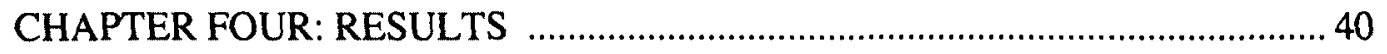

Participant Characteristics ................................................................. 41

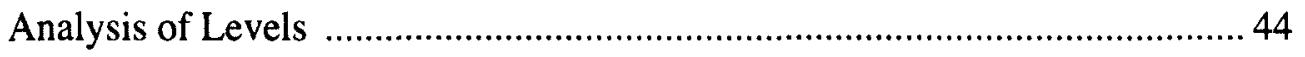

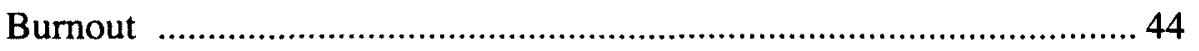

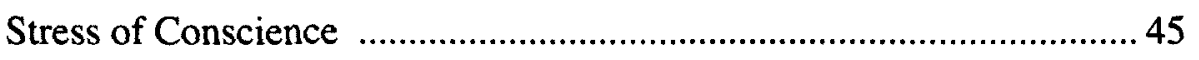

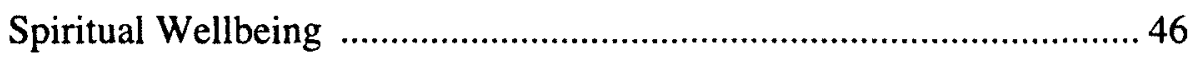

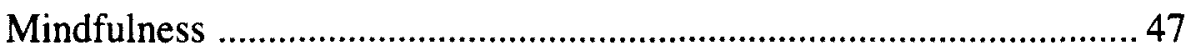

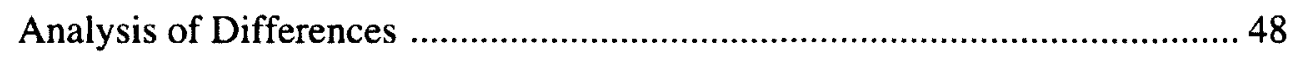

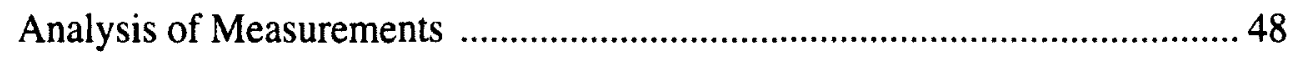

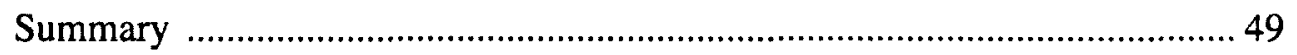

CHAPTER V: DISCUSSION AND CONCLUSION .......................................5 50

Summary of the Research Design and Method .............................................. 50

Summary and Discussion of Research Findings ....................................... 51

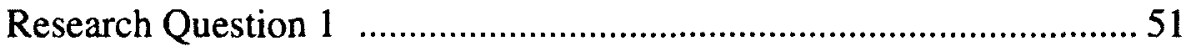

Research Question 2 ............................................................... 53

Implications for Nursing Science .......................................................... 59

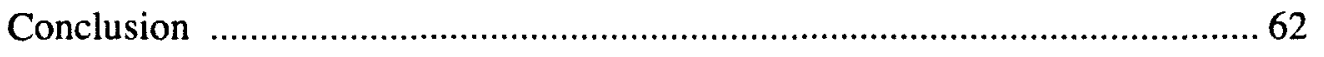




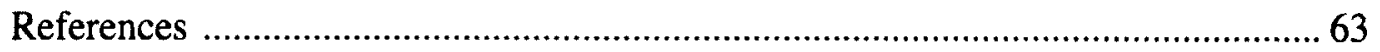




\section{LIST OF TABLES}

Table 1: Maslach Burnout Inventory-General Survey Scoring ............................. 33

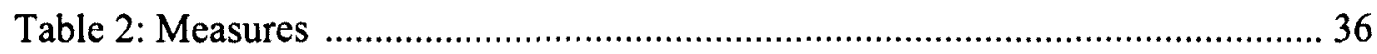

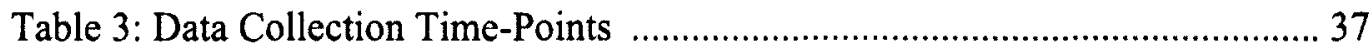

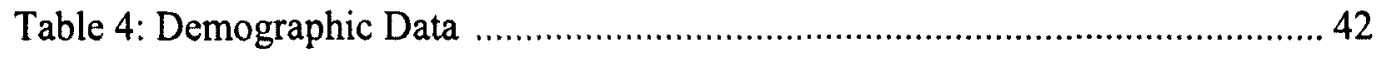

Table 5: Maslach Burnout Inventory-General Survey Scores ............................. 44

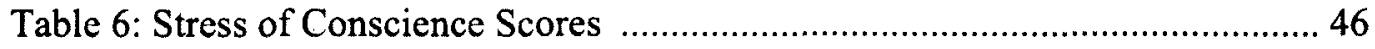

Table 7: Functional Assessment of Chronic Illness Therapy Spiritual Wellbeing

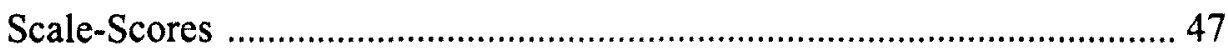

Table 8: Mindfulness Attention Awareness Scale Scores …............................... 48 


\section{LIST OF ILLUSTRATIONS}

Figure 1. Conceptual Framework ………………....................................... 10 


\section{LIST OF APPENDICES}

Appendix A. University of San Diego Institutional Review Board

Appendix B. San Diego Veteran Affairs Healthcare Systems Research and

Development ....................................................................... 71

Appendix C. Instrument Permissions

76 


\section{CHAPTER I}

\section{INTRODUCTION}

The United States is facing an unprecedented healthcare crisis and healthcare workers (HCWs) are essential for the delivery of patient care. The United States Bureau of Labor Statistics (BLS) predicts the creation of 3.2 million new healthcare jobs by 2018 , largely due to the expanding elderly population (2011). Workforce issues of increasing occupational stress and burnout significantly affect individuals and organizations. According to the National Institute for Occupational Safety and Health (NIOSH), stress is a major concern for over 12 million American HCWs (2011). High patient acuity and heavy technology use coupled with increasing physical and emotional demands create a stressful work environment. Stress may lead to depression, decreased job satisfaction, and psychological distress in the individual HCW (NIOSH, 2008). Unrelieved stress results in burnout, a work-related stress syndrome first observed among healthcare workers in the mid-1990s (Maslach, Jackson, \& Leiter, 1996). Healthcare organizations are increasingly concerned about evidence that burnout compromises patient safety and negatively affects patient satisfaction and safety (McHugh, Kutney-Lee, Cimiotti, Sloane, \& Aiken, 2011). The antecedents to burnout are well known; however, research on interventions to 
reduce burnout has been limited (Maslach, Schaufeli, \& Leiter, 2001).

The overall purpose of this quasi-experimental study was to evaluate the efficacy of a structured internet-delivered Mantram Repetition Program (MRP) in decreasing burnout and stress of conscience and improving mindfulness and spiritual wellbeing in Veteran Affairs (VA) HCWs. The MRP was a structured educational program of skills training available to HCWs within the VA Healthcare System. The course objectives, which originate from Easwaran's Eight Point Program, include mantram repetition, slowing down, and one-pointed attention (Easwaran, 1993). The program taught participants how to repeat a Mantram, a sacred or spiritual word or phrase, silently and intermittently throughout the day to train their attention and redirect unwanted thoughts as a means of emotional self-regulation.

\section{Statement of the Problem}

The Institute of Medicine reported pervasive problems in the quality and safety of American healthcare in "To Err Is Human" (2000) and "Crossing the Quality Chasm" (2001). Increased national concern for safety and quality of care during hospitalizations serves as impetus for system changes to improve patient outcomes and satisfaction while containing costs (McHugh, Aiken, Cooper, \& Miller, 2008; Kutney-Lee, McHugh, Sloane, Cimiotti, Flynn, Neff, \& Aiken, 2009). As a result of this stress, HCWs experience a higher incidence of substance abuse, suicide, depression, and anxiety (NIOSH, 2008).

The BLS reported that the $60 \%$ of registered nurses (RNs) working within US hospitals constitutes the largest component of HCWs (BLS, 2011). The nursing workforce will need 285,000 registered nurses by 2020 and 500,000 by 2025 (Buerhaus, 
Staiger, \& Auerbach, 2008). Despite the staggering need for HCWs, the nursing population may diminish due to personal health concerns and attrition. Nearly half of the 1,399 nurses surveyed in 2010 were concerned that their job is affecting their health (AMN Healthcare, 2010). In 2008, 37\% of nurses employed in non-nursing occupations cited burnout or stressful work environments as the predominant reason for not working as a nurse (Department of Health and Human Services, 2012). Dissatisfaction was also cited as a major reason for nurses to prematurely exit the workforce (McHugh et al., 2011).

With a severe staffing shortage and predictions of increasing acuity of hospitalized patients, loss of qualified workers due to burnout will jeopardize safe patient care. The negative effects of workplace stress and burnout can lower patient satisfaction, compromise patient safety, and be costly for healthcare organizations (McHugh et al., 2011; Vahey, Aiken, Sloane, Clarke, \& Vargas, 2004; Marine, Ruotsalainen, Serra, \& Verbeek, 2006).

Work-related stress and burnout are major concerns in the healthcare field. Stress is defined as the physiological and psychological response to a situation that creates physiological arousal and mobilization of psychological coping mechanisms (Cannon, 1953; Lazarus \& Folkman, 1984). Burnout is used to describe workers' response to prolonged stress (Freudenberger, 1974), and for the purposes of this study, the term is defined as a syndrome in which people suffer from exhaustion, cynicism, and reduced professional efficacy (Schaufeli, Leiter, Maslach, \& Jackson, 1996).

The concepts of distress and burnout as deterrents to spiritual wellbeing and mindfulness of HCWs have been explored (Alkrisat, 2011; Heard, 2010). Stress, both 
physical and psychological in nature, threatens the spiritual wellbeing of HCWs. Moral and ethical factors are pervasive within the HCWs environment, creating workplace stress. Examples of HCWs stress include the real or perceived inability and barriers to complete tasks or attend to patients' needs. Stressful situations may permeate the minds of HCWs and create a "stress of conscience," which is stress related to a troubled conscience (Juthberg, Eriksson, Norberg, \& Sundin, 2007). Kabat-Zinn (1994) defines mindfulness as the nonjudgmental state of being aware, attentive, and intentionally focused in the present moment. The state of mindfulness can be attained with practice. Mindfulness can enhance awareness and assist with the ability to disengage from ruminative thoughts.

\section{Background and Significance}

Burnout is a multifaceted phenomenon influenced by external and internal factors. Antecedents and potential consequences of burnout are well documented in the healthcare literature (Maslach \& Jackson, 1981; Maslach, Schaufeli, \& Leiter, 2001). Lazarus and Folkman's (1984) transactional model of stress coping was used as the conceptual framework to guide this study. The underpinnings of this model support stress as a relationship ("transaction") between individuals and their environment.

Researchers note that burnout is largely related to external factors within the organizational structure (Aiken, Clark, Sloane, Sochalski, \& Silber, 2002; Aiken, Clark, Sloane, Sochalski, \& Busse et al., 2001). Although healthcare systems have offered strategies to support the employee work environment, burnout remains a prevalent problem.

Providing individual interventions for HCWs to cope with stress and burnout is 
equally important. One internal means of decreasing burnout is for $\mathrm{HCWs}$ to gain control of their negative thoughts and learn techniques to prevent unrelieved stress overload. Potential strategies include mind-body courses to reduce perceived workplace stress and burnout (Cohen-Katz, Wiley, Capuano, Baker, \& Shapiro, 2004). Kemper, Bulla, Krueger, Ott, McCool, and Gardiner (2011) found that nurses have positive attitudes toward mind-body therapies to reduce stress.

\section{Mantram Repetition Program (MRP)}

Mantram repetition, described as a "portable" contemplative tool, is a selected sacred word or phrase repeated silently and intermittently throughout the day to train attention and redirect unwanted thoughts. Mantram repetition is supported by the practices of intentionally slowing down and developing single-minded, one-pointed attention. Slowing down is being intentional during the present moment. One pointed attention is focused attention without distraction, and includes mantram repetition or a self-selected task.

Studies of the Mantram Repetition Program (MRP) have shown significant improvements in reducing stress and increasing quality of life and spiritual wellbeing for Veterans Affairs (VA) employees and Korean nurse managers (Bormann, Becker, Gershwin, Kelly, Pada, Smith, \& Gifford, 2006; Bormann, Oman, Kemppainen, Becker, Gershwin, \& Kelly, 2006; Yong, Kim, Park, Seo, \& Swinton, 2011).

The internet-delivered MRP used in this study consists of lecture, discussion and instruction in mantram repetition, slowing down, and one-pointed attention as stress reduction strategies. The "live meeting" interactive-intranet format is a virtual meeting space that allows participants to hear live audio and view PowerPoint presentations on 
their computers while participating in a conference call.

Empirical evidence suggests that burnout is a significant problem in healthcare (Browning, Ryan, Greenberg, \& Rolniak, 2006; Komala \& Ganesh, 2007). Reducing burnout is an effective strategy to improve HCWs' wellbeing, especially in the context of an HCW shortage and emphasis on safe, effective patient care (Poghosyan, Clarke, Finlayson, \& Aiken, 2010). In spite of research, significant gaps about tools in the literature exist for HCWs in managing stress and reducing burnout. Although each of these studies contributed significantly to the literature on fostering coping strategies among HCWs, only one directly evaluated the relationship of an MRP to burnout. In that study the intervention was delivered in traditional classroom setting, which can be time consuming and costly. The current study analyzed data derived from a prior study to illuminate benefits of the MRP. This study was an initial and important attempt in determining if an internet-delivered MRP reduces burnout and stress of conscience and improves spiritual wellbeing and mindfulness.

\section{Statement of Purpose}

The purpose of this study was to evaluate the relationship of a structured internetdelivered MRP on burnout, stress of conscience, mindfulness, and spiritual wellbeing. The study goal was to increase knowledge of the MRP as it relates to potential benefits to HCWs. Understanding the relationship of burnout, stress of conscience, mindfulness, and spiritual wellbeing may guide in creating a healthy work environment, decreasing employee healthcare costs related to stress, and offering meaningful approaches to improving HCWs' wellbeing. 


\section{Specific Aims of Study}

Providing care as a HCW has been described as stressful and can lead to burnout. Improving spiritual wellbeing and mindfulness may decrease burnout and stress of conscience. The study aims of this research were designed to examine the relationship of a MRP with several factors. The specific aims of this study were to:

1. Describe relevant demographic and professional characteristics of a group of HCWs participating in a structured internet-delivered MRP;

2. Describe levels of burnout, stress of conscience, spiritual wellbeing, and mindfulness in a group of $\mathrm{HCWs}$ at baseline, post-intervention and three months following participation in a structured internet-delivered MRP; and

3. Determine if significant differences exist across relevant demographic and professional characteristics in levels of burnout, stress of conscience, spiritual wellbeing, and mindfulness at baseline, post-intervention and three months after participation in a structured internet-delivered MRP.

The following questions guided this research study:

1. What are the relevant demographic and professional characteristics of a group of HCWs participating in a structured internet-delivered MRP?

2. What are the levels of burnout, stress of conscience, spiritual wellbeing, and mindfulness in a group of HCWs at baseline, post-intervention, and three months following participation in a structured internet-delivered MRP?

3. Do significant differences exist across relevant demographic and professional characteristics in levels of burnout, stress of conscience, spiritual wellbeing, and 
mindfulness at baseline, post-intervention, and three months after participation in a structured internet-delivered MRP?

The long-term goals of the trajectory of research on the MRP are to determine if the MRP leads to increased spiritual wellbeing and mindfulness and decreased burnout and stress of conscience in HCWs. Intervention programs for improving health and decreasing stress and burnout rates amongst HCWs need further exploration, as there is limited evidence available for the effectiveness of self-initiated interventions in reducing burnout and a severe shortage of HCWs looming (Cohen-Katz, Wiley, Capuano, Kimmel, \& Shapiro 2005; Günüşen \& Üstün, 2010; Suzuki, Itomine, Kanoya, Katsuki, Horii, \& Sato, 2006). 


\section{CHAPTER II}

\section{REVIEW OF THE LITERATURE}

This chapter outlines the conceptual framework for this study. The transactional model of stress and coping that provided study direction will be presented, particularly its relevance to burnout and the $\mathrm{HCW}$. Theoretical definitions and a review of relevant literature to outline the state of the science will be presented. Assumptions and limitations will be outlined. An explanation of this dissertation's importance will be described in relation to the advancement of knowledge about effective self-initiated interventions in reducing burnout and stress of conscience and improving spiritual wellbeing and mindfulness.

\section{Conceptual Framework}

Lazarus and Folkman's (1984) transactional model of stress and coping provides the conceptual framework for this study (Figure 1). The transactional stress and coping model focuses on the concept that stress is a relationship or "transition" between individuals and their environment. Stress is defined as "a particular relationship between the person and the environment that is appraised by the person as taxing or exceeding his or her resources and endangering his or her wellbeing" (Lazarus and Folkman, 1984, p. 19). 


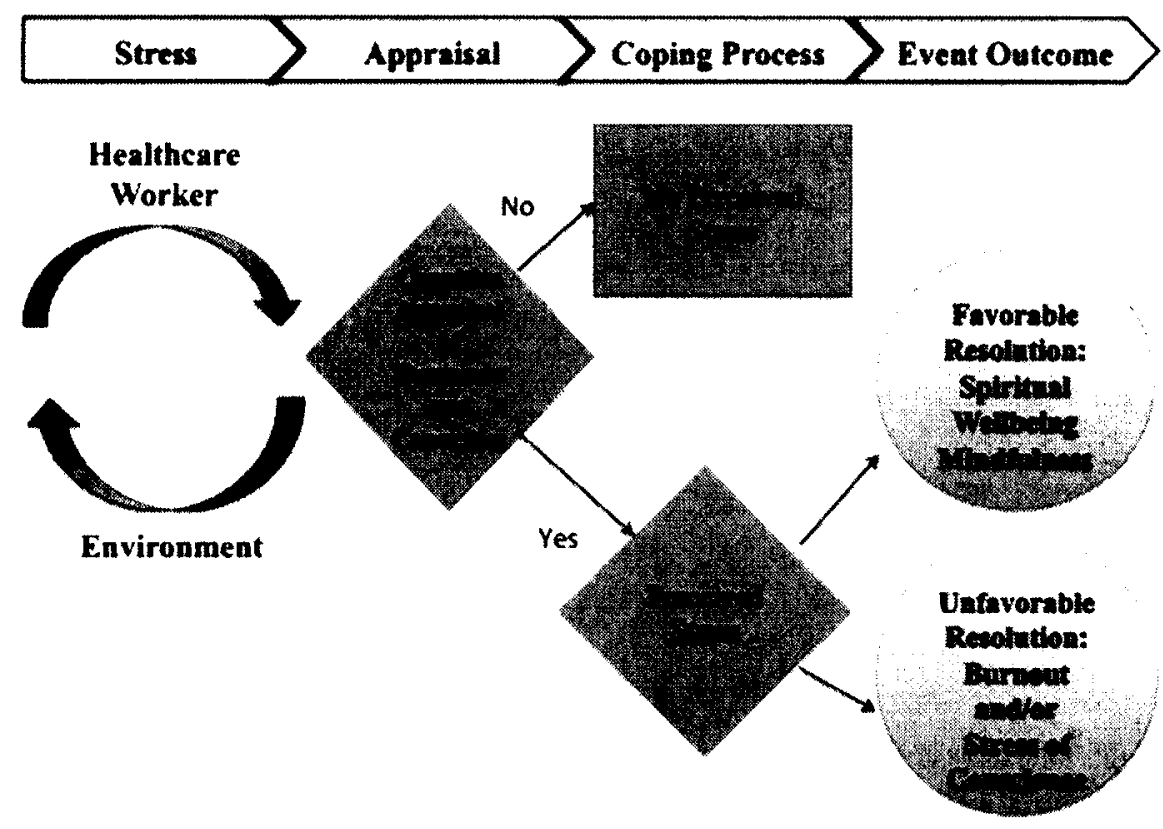

Figure 1. Conceptual framework.

This model asserts the person's reaction to stress is dependent on their appraisal of both the harmfulness of an event and their perceived coping abilities to deal with the external situation. Two key processes that occur in this model are cognitive appraisal and coping. Cognitive appraisal is a person's assessment of the perceived stressor. The appraisal, either assessed to exceed the current demands or be within current capacities, determines how well one will cope with the stressor. The model purports that an individual's perceived control of stressful situations affect coping. The individual is more likely to be affected by stress when control is perceived to be external than if the individual feels an internal sense of control (Folkman \& Lazarus, 1984).

Lazarus and Folkman (1984) define coping as "constantly changing cognitive and behavioral efforts to manage specific internal and/or external demands that are appraised as taxing or exceeding the resources of the person"' (p. 141). The coping process, 
whether problem-focused or emotion-focused, leads to either a favorable or unfavorable event outcome. Concrete attempts to change the stressful event are problem-focused coping. Attempts made to alter the stressful feelings are emotion-focused coping. Key to both coping strategies is the exertion of control over situations and the ability to reach a resolution, either favorable or unfavorable (Folkman \& Lazarus, 1984). Individuals can learn to manage their stress and cope with stressors through learning problem-focused or emotion-focused coping strategies. The model supports perceived stress as a relationship ("transaction") between individuals, defined here as HCWs, that may be unfavorably processed, measured as burnout. The conceptual framework guides this study because burnout and stress of conscience are examples of maladaptive coping and spiritual wellbeing and mindfulness are examples of adaptive coping.

\section{Theoretical Definitions}

Several theoretical and operational definitions guide this study.

\section{Healthcare Worker (HCW)}

Healthcare systems employ HCWs with varying levels of education and training to provide a service to recipients of healthcare. The employees make up a variety of service occupations to include registered nurses (RNs), physicians, surgeons, therapists, and social workers. Healthcare systems also employ large numbers of office and administrative support (BLS, 2011).

The operational definition of HCW is a VA Healthcare System employee who voluntarily enrolled in the MRP Live Meeting series through VA Employee Education System (EES) from March 8, 2012 to August 31, 2012. 


\section{MRP}

The MRP originates from Easwaran's Eight Point Program that includes passage meditation, mantram repetition, slowing down and focused/one-pointed attention, training the senses, putting others first, spiritual association, and inspirational reading (Easwaran, 1993). It is a nonsectarian, spiritually based, self-initiated educational program.

For this study, MRP was an educational program of skills training available to HCWs of the entire healthcare system. The course objectives included three from Easwaran's Eight Point Program: mantram repetition, slowing down, and one-pointed attention (Easwaran, 1993). Mantram repetition is described as a "portable" contemplative tool, involving a self-selected "sacred" word or phrase (e.g. "My God and my all") repeated silently and intermittently throughout the day to train attention and redirect unwanted thoughts.

Slowing down and one-pointed attention support mantram repetition. Slowing down, or being intentional during the present moment, occurs during a self-selected prioritized task performed within a structured period with the goals of increasing awareness and promoting self-reflection. An example of slowing down would be a nurse meticulously attending to the details of the patient's needs. One-pointed attention is focused attention without distractions that is first practiced with mantram repetition. The opposite of multi-tasking, it is being single-minded externally during a self-selected task to enhance concentration during activities or internally on thought or mantram. An example of one-pointed attention would be a nurse focusing on medication administration without simultaneously answering a text page from a physician. 
The structured, internet-delivered program was composed of six 50 minutes classes: Class 1- Introduction to Mantram Repetition; Class 2- How to Choose, Use, and Track Mantram Practice; Class 3- The Stress Response and Mantram Repetition; Class 4Slowing Down; Class 5- One-Pointed Attention; and Class 6- Putting it All Together. The classes were offered on a biweekly basis over a three-month period. Participants were given a training manual that incorporated homework assignments and a course textbook with weekly reading assignments.

\section{Burnout}

Burnout is defined as workers' response of physical and emotional exhaustion that involves a negative attitude toward one's job and/or profession (Freudenberger, 1974). For this study, burnout was measured using the Maslach Burnout InventoryGeneral Survey (MBI-GS) by Schaufeli, Leiter, Maslach, \& Jackson (1996). The MBIGS is a 16-item questionnaire that measures exhaustion (EX), cynicism (CY), or the development of cynical attitudes towards job or recipients of service, and perceptions of diminished professional efficacy (PE; Schaufeli et al., 1996).

\section{Stress of Conscience}

Stress of conscience is related to HCW' feelings of inadequacy in meeting the demands associated with good care. Examples of stress of conscience include the real or perceived inability to complete tasks or attend to patients' needs. Stressful situations may permeate the minds of $\mathrm{HCWs}$, creating a stress of conscience or stress related to a troubled conscience (Juthberg et al., 2007).

Stress of conscience was measured using the Stress of Conscience Questionnaire (SCQ), a nine-item instrument that assesses internal demands, provision of care and 
external demands, and conflicts with personal conscience on a 6-point Likert-type scale (Glasberg et al., 2006).

\section{Spiritual Wellbeing}

Spiritual wellbeing was defined as the overall measure of the perception of existential spiritual quality of life. For purposes of this study, existential spiritual wellbeing was measured using the general non-illness version of Functional Assessment of Chronic Illness Therapy Spiritual Wellbeing Scale-12 items (FACIT-SP) on a 5 point Likert-type scale (Peterman, Fischett, Brady, Hernandez, \& Cella, 2002).

\section{Mindfulness}

Mindfulness is a way of purposefully paying attention in the present moment without judgment (Kabat-Zinn, 1994). For this study mindfulness was defined as an intentional, nonjudgmental focus on the present moment. This study measured mindfulness using the Mindfulness Attention Awareness Scale (MAAS; Brown \& Ryan, 2003), a 15-item self-report instrument that measures mindfulness of everyday activities.

\section{Principal Literature Review}

Literature related to $\mathrm{HCW}$ burnout is copious; however, it generally consists of descriptive, cross-sectional studies. In the general healthcare burnout literature, the majority of studies focus on HCWs' external environment as a contributor to burnout and cite possible solutions to be employed by managers and/or hospital administrators. Limited evidence is available to support self-initiated interventions aimed at reducing stress levels and burnout (Marine et al., 2006). A literature review was done to explore self-initiated interventions for HCWs in preventing or lessening burnout without the influences of organizational culture and physical environment. Self-initiated interventions 
reported in the literature included personal skills, techniques, or remedies to decrease individual burnout. Examples include mitigating the effects of stress by using relaxation or cognitive-based techniques.

A comprehensive search was done from 10 databases: Academic Search Premier, Cumulative Index to Nursing Allied Health Literature (CINAHL) Plus with Full Text, Health Source: Nursing/Academic Edition, Ovid, JSTOR Archive Collection, Springerlink Contemporary, Wiley InterScience Journals, PsycINFO, Sociological Collection, Science Direct, and Sage. The search parameters were research-based, nondescriptive studies conducted between 1985 and 2012, peer-reviewed scholarly journals with the following as search terms: healthcare worker, environment, burnout, mantram repetition, stress, stress of conscience, spiritual wellbeing, and mindfulness. Additional citations were identified from reference lists of related articles. All searches were limited to articles with human subjects and published in English. Articles were excluded if they lacked self-initiated interventions aimed at burnout. The final number of research articles reviewed that employed self-initiated training to decrease burnout among HCWs was six. Additionally, four research articles to enhance HCWs' wellbeing specifically using mantram repetition were reviewed.

Two themes that emerged from the study will guide the presentation of related research to illuminate gaps in the literature: studies using self-initiated interventions for burnout among HCWs and studies using the mantram repetition intervention.

\section{Self-Initiated Interventions for Burnout}

In a randomized control trial of 118 healthcare providers, beneficial effects were demonstrated using a stress management intervention evaluated using three subscales: the 
MBI, emotional exhaustion (EE), depersonalization (DP) or the development of cynical attitudes towards job or recipients of service, and perceptions of diminished personal accomplishment (PA; Rowe, 1999). Stress management interventions to teach healthcare providers how to develop problem-focused and emotion-focused strategies to address problems and cope when solutions are not available. Subjects were randomized into three equal groups: an intervention group $(n=42)$, an intervention group with refresher follow up $(n=42)$, and a control group ( $n=42)$. The three groups had no significant differences between EE and PA scores at baseline. The two intervention groups had significantly lower scores on EE and PA at two and six-month intervals compared to the control group. The refresher follow up group had mean differences to include a higher sense of PA and lower $\mathrm{EE}$ at the one and two year longitudinal measures.

These findings demonstrate that healthcare providers can be taught coping strategies to combat stress and experience less burnout. A major strength of the findings is the suggestion that education directed at proactive, long-term coping strategies becomes more effective in minimizing burnout subscale scores over time. While this is an excellent start, further research is needed to control for the potential intrinsic motivation and commitment of the HCWs to employ cognitive and behavioral changes. Although the participants were reported as a normative sample, demographic variables were not controlled as a potential variable contributing to burnout.

Cohen-Katz et al. (2005) conducted a pretest-posttest waitlist control group design with randomization to employ self-initiated training using a cognitive based program of Mindfulness-Based Stress Reduction (MBSR). The study aims were to enhance communication skills, stress reactivity, and self-compassion. The eight-week 
program consisted of group sessions that met 2.5 hours per week to include formal didactic instruction and exercises. The HCW participants $(\mathrm{n}=25)$, the majority of which were nurses, were randomly assigned to a treatment group $(n=12)$ or waitlist control group ( $\mathrm{n}=13$ ). All participants were measured on burnout using the MBI, psychological distress using the Brief Symptom Inventory, and mindfulness using the MAAS prior to intervention, immediately following completion, and three months post-intervention. Results showed no significant differences between the intervention and control group prior to the program. Cohen-Katz et al. (2005) found statistically significant positive differences between the intervention and control groups on the mean change scores of mindfulness. Statistically significant reductions were found in the EE and PA subscales of the MBI scale immediately after and three months post-intervention from within-group analysis on the intervention group. The study strengths include the randomized research design and the new knowledge gained on an intervention affecting burnout. The authors reported this as a pilot study and concluded that the small sample size was a limitation.

Shapiro, Astin, Bishop, and Cordova (2005) conducted a randomized control trial pilot study to examine the potential positive effects of MBSR amongst HCWs specifically working in clinical settings. The intervention was an eight-week program with a sample of 38 participants assigned to either the intervention group $(n=18)$ or the waitlist control group $(\mathrm{n}=20)$. Psychological measures were collected at baseline and post intervention including the Brief Symptom Inventory, burnout using the MBI, stress using the Perceived Stress Scale, satisfaction with life using the Satisfaction With Life Scale (SWLS), and self-compassion with the Self-Compassion Scale. A regression analyses was conducted to control for initial group differences of some variables. Ten participants 
in the intervention group and 18 participants in the control group completed the program. Statistically significant improvements were observed in the intervention group in the Perceived Stress $(p=.04)$ and Self-Compassion Scale $(p=.004)$. Although improvements were demonstrated in the other measures, no statistically significant improvements in burnout were observed, possibly due to the small sample size. Study strengths include the randomized control design and positive impact of MBSR on participants. The study limitations include the lack of participant characteristics, small sample size, and high attrition rate. The authors did include rationale for participants dropping out of the study. McKenzie et al. (2006) studied the efficacy of a condensed, four-week version of an MBSR program on stress in nurses and nurse aides in non-direct care areas in Canada. The design was a randomized control pilot with the intervention of four 30-minute sessions. Thirty participants were randomly assigned to either a waitlist control group $(n=14)$ or to an intervention group ( $n=16)$. Psychometric instruments were used to measure burnout, work satisfaction, stress and relaxation and measured at baseline and at the completion of training. Repeated measures of analyses of variance (ANOVA) were performed on the effects of participation over time. Statistically significant lower burnout scores were achieved in all three subscales of the MBI (EE, DP, and PA). The results support that a self-initiated training decreases burnout amongst HCWs. While the findings are encouraging, study limitations include the inability to generalize the findings due to the heterogeneous sample of nurses and nurse aides, modest sample size lacking statistical power, and lack of follow up.

A randomized control trial was conducted by Oman, Hedberg, and Thoresen (2006) to evaluate passage mediation on perceived stress of HCWs. The authors defined 
passage mediation as the silent repetition of a memorized passage practiced for one-half hour each morning. Passage mediation and mantram repetition are both derived from Easwaran's Eight Point Program; however, mantram repetition is the repeated word or phrase used outside of meditation (Easwaran, 1993). The program was taught in two-hour classes over eight weeks with HCWs randomized to either a treatment group $(n=27)$ or waitlist control group $(n=31)$. Assessments were done at four time-points: pretest baseline, upon intervention completion, eight weeks, and 19 weeks post-intervention. The assessments measured eight stress and wellbeing outcomes variables, including burnout using the MBI. Statistically significant reductions in perceived stress were found at all four time-points. Unfortunately, no statistically significant changes were demonstrated in any of the three subscales of burnout. A major study strength is the promising relevance in reducing HCWs' perceived stress over time using a spiritual-based intervention. Inability to generalize is a limitation due to the participants' self-selection into the program and homogenous population.

Günüşen and Üstün (2010) examined the effects of coping training and social support group interventions in reducing burnout among nurses in Turkey. Questionaires were sent to 227 nurses working in a general inpatient university hospital. An invitation to participate in the study was sent if the nurse completed the questionaire and scored high on the EE subscale of the MBI compared with the median score from the general population. A sample of 108 nurses was randomized into either a coping group $(n=36)$, support group ( $n=36)$, or control group $(n=36)$.

The coping intervention consisted of seven sesssions, 90 to 120 minutes in length, that covered cognitive coping strategies and problem-solving methods. The support 
intervention objectives were to provide support, information, and a sense of belonging and to create a sharing environment. (The article did not include the frequency or length of the support group intervention.) The control group received the intervention after the final data collection. Two-factor repeated-measures of analysis of variance and paired $t$ tests were used to determine the effectiveness of the interventions. Due to the total sample dropout of 32, intention-to-treat analysis was used. Pre-intervention comparison of the groups' demographic variables and burnout rates showed no significant differences. The results were that EE scores decreased at the conclusion of the coping group intervention but were not sustained over time and increased six months after the intervention. No other significant findings were noted in this study. Limitations include the sample dropout during the course of the study, a homogeneous sample made up of entirely female nurses, and lack of indepth information about the support group intervention.

\section{Mantram Repetition Program}

Two qualitative and two quantitative studies utilizing mantram repetition were reviewed for this study. MRP has demonstrated significant changes among HCWs in spiritual and psychosocial outcomes that include stress, trait-anxiety, trait-anger, quality of life, spiritual wellbeing, leadership practices and burnout.

A qualitative study using the critical incident method was conducted by Bormann et al. (2006) to explore ways MRP was helpful to both participants (veterans) and HCWs. Inclusion criteria for participants were completion of an MRP and using the learned techniques. The final sample included 30 veterans and $36 \mathrm{HCWs}$; this review focuses on the HCWs' results. Participant data were collected by audiotaped telephone interviews 3 - 
6 months after completion of the MRP. A total of 147 incidents were reported, 76 of which came from the HCWs using MRP techniques. Results included incidents that fell into the following major categories: emotion other than stress using mantram repetition $(n=35)$, stress using mantram repetition $(n=22)$, sleep/insomnia $(n=10)$, unwanted thoughts $(n=4)$, and unwanted thoughts using one-pointed attention $(n=5)$. Although the majority of HCWs reported beneficial effects upon completion of the MRP, one HCW did not find the techniques helpful and stated it "interfered with emotions."

A limitation of this study is the single setting limiting generalizability. Study strengths were the inclusions of a critical incident research method expert and the rigorous design. The major contribution of this study is the exploration of HCWs' coping interventions using MRP techniques. The results were that techniques taught in an MRP are acceptable and useful to HCWs in managing situations.

Bormann et al. (2006) conducted a non-experimental, one group, pretest-posttest study to examine the feasibility and efficacy of the MRP on measures of stress, traitanxiety, trait-anger, quality of life, and spiritual wellbeing. A convenience sample of 42 volunteer HCWs attended five 90-minute classes that included lectures, group discussion, and exercises over five weeks. Course content emphasis was placed on facilitating mantram repetition practice. During this course, mantram repetition was supported by the practices of intentionally slowing down and developing single-minded, one-pointed attention. Psychometric instruments included Cohen's Perceived Stress Scale, Spielberger's State/Trait Anxiety Inventory, Spielberger's State/Trait Anger Inventory Short Form, Endicott's Quality of Life Enjoyment Short Form, and the Spiritual Wellbeing Scale. 
Repeated measures of analysis of variance (ANOVA) were performed on the variables to determine the effects of participation. Participants tracked mantram repetition frequency using wrist-worn counter devices and were categorized as either low or high users. Repeated measures of ANOVA were performed to compare groups. A Pearson correlation was done to determine a relationship between effects of mantram repetition frequency. Results of this study suggest that mantram repetition is a feasible and effective stress management strategy that demonstrates significant pre- to post-test improvements in stress, trait-anxiety, trait-anger, quality of life, and spiritual wellbeing. There were statistically significant reductions in perceived stress and improvements in spiritual wellbeing. A study strength was having participants with varying roles within healthcare, creating a heterogeneous group. Limitations were self-selected sample and no control group. This study demonstrated that a portable, self-initiated intervention can be employed within the healthcare workplace. While this is a groundbreaking, excellent study, further research is warranted to address the study limitations of lacking a comparison group within the design and small sample size.

A qualitative study by Richards, Oman, Hedberg, Thoresen, and Bowden (2006) examined 12 nurse participants' experiences upon completion of a spiritually-based program founded on Easwaran's Eight Point Program (Easwaran, 1993). The study aims were to explore the practicality of the learned techniques for nurses and determine whether application resulted in positive changes to stressful clinical situations. The program included two-hour classes over eight weeks with HCWs randomized to either a treatment group $(n=27)$ or waitlist control group $(n=31)$. Only data from the nurse participants were included in this article. Semi-structured, audiotaped telephone 
interviews of 12 participants from both groups were conducted an average of 15.6 weeks post course completion. A category that emerged from the interviews was workplace stress, which included emotional distress, fatigue, and burnout. When queried about motivations for entering the study, participants cited wanting to decrease anger and feelings of fragmentation, stress, and burnout. Most participants (11 of 12) expressed an increased ability to perform within the workplace. Unfortunately, participants also articulated concern about the barrier of time to continue passage meditation, one of the learned interventions. A major contribution to the science is the specific participants' emphasis on four self-initiated skills (Mantram, Slowing Down, One-Pointed Attention and Putting Others First) as contributors to decreasing participants' perceived workplace stress.

Yong et al. (2011) measured spiritual wellbeing, spiritual integrity, leadership practice, job satisfaction, and burnout in 51 Korean middle management nurses. The study design used an experimental group $(n=24)$ and control group $(n=27)$ to examine outcomes of a spirituality training program. The program emphasized mantram repetition, slowing down, and one-pointed attention, originating from Easwaran's Eight Point Program (Easwaran, 1993). The curriculum consisted of five 90-minute classes that included lectures, small-group work, and dedicated time for practice of newly learned skills over five weeks. Data were collected pre- and post-intervention on the Spiritual Wellbeing, Spiritual Integrity, MBI, Leadership Practice Inventory, and Job Satisfaction constructs. Data analyses included $t$ tests and an analysis of covariance (ANCOVA). There were no statistically significant demographic differences between the two groups. Study results indicated the experimental group had statistically significant higher spiritual 
wellbeing, spiritual integrity, and leadership practices than controls. The major finding of this study included the experimental group reporting statistically significant lower burnout scores $(p=.000)$. Although this study demonstrated evidence to support the use of mantram repetition, limitations include the lack of follow-up results over time and a small sample size.

\section{Summary of Literature Review}

The search for evidence of self-initiated interventions for HCWs to manage burnout yielded six studies. The paucity of self-initiated intervention studies limits the ability to draw strong conclusions on the benefits of self-initiated interventions. Strength of evidence overall was moderate for $\mathrm{HCW}$ s benefitting from self-initiated measures to decrease burnout. Most of the evidence was rated moderate due to limitations of small sample size and lack of follow-up over time. Four studies were reviewed to evaluate effectiveness of MRPs on wellbeing and psychological measures among HCWs. There was sufficient evidence that MRP positively benefits HCWs but limited data on the effects of burnout, stress of conscience, spiritual wellbeing, and mindfulness.

Addressing the issue of safe and effective delivery of care to patients in the midst of competing healthcare priorities is a complex problem. The focus on the health and wellbeing of HCWs may indirectly improve healthcare quality. From a conceptual framework, interventions to mitigate perceived stress and burnout are warranted. Unmitigated perceived stress leads to HCW burnout, consisting of depersonalization, emotional exhaustion, and a feeling of lacking personal accomplishment. Favorable resolutions of perceived stress are important to HCWs' wellbeing and may translate to improved patient care and safety. 


\section{Importance to the Advancement of Knowledge}

The review of the literature supports the conceptual framework and research design of this study. It is important to explore self-initiated interventions that may reduce burnout experienced by HCWs. In the general burnout literature, the majority of the studies focus on HCWs' external environment as a contributor to burnout and cites possible solutions to be employed by managers and/or hospital administrators versus the internal locus of control within the HCW. This literature review points to limited knowledge on successful self-initiated interventions to address burnout in HCWs.

In summary, the review of the literature indicates that further research is needed to evaluate ways $\mathrm{HCWs}$ can gain internal control to decrease burnout. Specificially related to MRP, five previous studies have demonstrated the beneficial effects for HCWs (Oman, Hedberg, \& Thoresen, 2006; Bormann et al., 2006; Richards et al., 2006; Yong, et al., 2011). Although these studies contribute significantly to the literature on providing coping strategies to HCWs, all except one do not directly evaluate the relationship of the MRP on burnout.

The current study examined the relationship by conducting analyses of data derived from a prior study to illumniate the benefits MRP may have for burnout and any relationships between stress of conscience, spiritual wellbeing, and mindfulness in HCWs. Stress of conscience, spiritual wellbeing, and mindfulness were included to control for cofounding variables. Results from this study may inform adminstrators as they endeavor to increase the supply of qualified staff and employ measures to improve patient outcomes. Therefore, it would be highly contributive to the literature if the effects of MRPs are shown to have a relationship on burnout, stress of conscience, spiritual 
wellbeing, and mindfulness. Knowledge gained from this analysis may be used to support interventions designed to improve these factors in HCWs.

\section{Assumptions}

This study was based on the following assumptions:

1. HCWs can experience burnout and stress of conscience and decreased spiritual wellbeing and mindfulness.

2. HCWs want to lessen stress of conscience and strengthen spiritual wellbeing and mindfulness to alleviate burnout.

3. The independent variable, MRP, may not be the only effect on the dependent variables of burnout, stress of conscience, spiritual wellbeing, and mindfulness.

4. Participants answered surveys honestly.

5. Participants accurately reported their subjective feelings.

6. The chosen instruments accurately reported the concepts examined.

7. All information collected by the primary investigators is an accurate reflection of the intervention.

\section{Limitations}

This study was based on the following limitations:

1. Participants were obtained via a convenience sample of HCWs employed within the Veteran Affairs Healthcare System, thus limiting generalizability.

2. Sample bias may have occurred due to the voluntary basis of participation and self-reporting. 


\section{CHAPTER III}

\section{METHODS}

The purpose of this study was to examine the efficacy of an MRP on HCWs' selfreported behavioral outcomes, including burnout, stress of conscience, spiritual wellbeing, and mindfulness. This chapter describes the study design, setting, and protection of human as well as the sampling and data measurement, collection, management, and analyses processes.

\section{Specific Aims and Research Questions}

The specific aims of this study were to:

1. Describe relevant demographic and professional characteristics in a group of HCWs participating in a structured internet-delivered MRP;

2. Describe levels of burnout, stress of conscience, spiritual wellbeing, and mindfulness in a group of HCWs at baseline, post-intervention and three months following participation in a structured internet-delivered MRP; an

3. Determine if significant differences exist in levels of burnout, stress of conscience, spiritual wellbeing, and mindfulness at baseline, post-intervention, 
and three months after participation in a structured internet-delivered MRP across relevant demographic and professional characteristics.

The following questions guided this research study:

1. What were the relevant demographic and professional characteristics of a group of HCWs participating in a structured internet-delivered MRP?

2. What were the levels of burnout, stress of conscience, spiritual wellbeing, and mindfulness in a group of HCWs at baseline, post-intervention and three months following participation in a structured internet-delivered MRP?

3. Did significant differences exist in levels of burnout, stress of conscience, spiritual wellbeing, and mindfulness at baseline, post-intervention, and three months after participation in a structured internet-delivered MRP across relevant demographic and professional characteristics?

\section{Design}

Secondary analysis of a quasi-experimental, repeated measures, pretest-posttest and three-month follow-up design was used for this study. Secondary analysis is defined as "the use of existing data from a previous study to test new hypotheses or answer new questions" (Polit \& Beck, 2012, p. 266). The advantages to conducting a secondary analysis include the potential savings of finances, time, and resources (Polit \& Beck, 2012). The rationale for selecting this data set was that it had not undergone previous analysis and was readily available with permission from a colleague to conduct a thorough assessment of appropriateness to answer the research questions. 


\section{MRP Study}

This study used a convenience sample of volunteer participants who completed a structured internet-delivered MRP by Bormann et al. (2006) to evaluate its efficacy on burnout, stress of conscience, mindfulness, and spiritual wellbeing. Based on previous studies, there are supported relationships between burnout and stress of conscience, mindfulness, and spiritual wellbeing, but the relationships between them have not been examined. A repeated measures prospective design was used to evaluate the effectiveness of decreasing burnout and stress of conscience and enhancing mindfulness and spiritual wellbeing. Data were collected at baseline, immediately after the intervention, and three months post-intervention.

\section{Setting}

The study was conducted within a national healthcare system with $125 \mathrm{HCWs}$ voluntarily enrolled in the MRP series coordinated with the education department. Recruitment occurred prior to the start of the MRP by direct and indirect means including advertising flyers and blinded group emails advertising the course. Recruitment material was included as part of the facility's Institutional Review Board (IRB) application package. Selection criteria included employment within the healthcare system and enrollment in the MRP. IRB approval was obtained prior to recruitment for the study. HCWs' participation was voluntary and consent was implied with initial online survey submission. Of the 54 participants who consented to be part of the study and completed the pretest survey, $39(72 \%)$ completed surveys at all three time-points. 


\section{Power Analysis}

The type of statistical test, sample size and effect being measured, and level of error all influence the power analysis. The sample size required to demonstrate an effect can be a study limitation. A small effect may require a large sample, which may be difficult for recruitment. The original investigators were limited by the technological constraints of EES, as the limit was 125 participants. For this study, analyses were conducted on the 39 participants who completed the three surveys over six months. For this sample size, a power analysis conducted to detect a medium effect size $(f=.25$, setting alpha at 0.05 , with $\mathrm{r}=.5$ ) yielded power greater than .92 .

\section{Protection of Human Subjects}

The original investigators submitted the study proposal to the Veteran Healthcare Affairs San Diego Research and Development Committee and the University of California San Diego Human Service Protection Program to protect participants from risk or injury. Approval was granted from both agencies. For the secondary analysis, this investigator submitted and gained approval of the proposal from the IRB of the University of San Diego (Appendix A).

To make every effort to maintain confidentiality and anonymity, all information was handled as confidentially as possible and to the extent provided by law. All surveys were identified with a unique number code rather than name or other identifying information. All electronic data were password protected and housed on secure servers.

One master list with identifying data matching codes with names was kept by the investigator in a locked cabinet. Only the approved study personnel had access to files. 
All of these individuals have passed an exam on confidentiality and understand the enforcement of this policy. Names were not used in any published reports about the study.

\section{Sample and Sampling}

The study was conducted from the VA San Diego Healthcare System with volunteer HCWs from any VA nationwide who enrolled in the MRP live meeting series coordinated with the VA Employee Education Services (EES). Course enrollment was $125 \mathrm{HCWs}$ with 54 enrolling in the original study.

Recruitment occurred prior to the start of the intervention by direct and indirect means. Flyers advertising the course were posted with a statement sent in a blinded (bcc) group email: "By taking the course, you agree that you may be contacted by email to participate in a VA study to evaluate the Mantram Repetition Program." When potential participants signed up for the MRP program, they received a course description and course brochure that stated, "By taking the course, you agree that you may be contacted by email to participate in a VA study to evaluate the Mantram Repetition Program." Recruitment material was included as part of the facility's IRB application package.

\section{Operational Definitions}

\section{MRP}

The structured internet-delivered program consisted of six 50-minute classes based on the following outline: Class 1-Introduction to Mantram Repetition; Class 2-How to Choose, Use, and Track Mantram Practice; Class 3-The Stress Response and Mantram Repetition; Class 4-Slowing Down; Class 5-One-Pointed Attention; and Class 6-Putting It All Together. The classes were offered biweekly over a three-month period. 
Participants were given a training manual that incorporated homework assignments and a course textbook with weekly reading assignments.

Each 50-minute class consisted of lecture and discussion that was facilitated synchronously via the Internet using an interactive virtual meeting format that allowed participants to hear live audio and view PowerPoint presentations on their computers. Information was exchanged when participants asked questions using live meeting technology or telephone conference calls. The program objectives included three primary stress reduction strategies from Easwaran's Eight Point Program: mantram repetition, slowing down, and one-pointed attention (Easwaran, 1993).

\section{HCW}

The operational definition of HCW was a VA Healthcare System employee enrolled in the MRP live meeting series through VA EES.

\section{Measurements}

\section{Burnout}

For this study, burnout was measured using the MBI-GS by Schaufeli et al. (1996). The MBI-GS is a 16-item questionnaire with a Likert-type scale ranging from 0 ("never") to 6 ("every day") that measures three antecedents of burnout: feelings of exhaustion (EX), distancing attitudes towards job or recipients of service (CY), and negative self-perceptions and feelings of not performing tasks adequately (PE). The items present statements about personal feelings, and respondents report the frequency with which they experience these feelings.

Based on factor analyses and psychometric findings in a variety of populations, the authors of the MBI-GS suggest that subscale scores not be combined into an overall 
score but reported as individual subscale scores (Maslach \& Jackson, 1996). For this reason, it should be noted that separate analyses of MBI-GS subscales were done for this study. Higher scores on the EX and CY subscales correspond with higher levels of burnout. PE is scored in the opposite direction as low scores correspond with higher levels of burnout. These relationships were supported in this study.

Table 1

Maslach Burnout Inventory-General Survey Scoring

\begin{tabular}{l|l|l|l}
\hline \multicolumn{2}{l}{ EX } & \multicolumn{1}{l}{ CY } \\
\hline High & 16 or over & 13 or over & 30 or over \\
Moderate & $8-15$ & $6-12$ & $24-29$ \\
Low & $0-7$ & $0-5$ & $0-23$
\end{tabular}

Subscale scores are categorized in terms of low, moderate and high. A high score falls within the upper third of the normal distribution; average is within the middle of the distribution, and low within the lower third (Maslach et al., 1996). The MBI-GS has shown to be a reliable and valid instrument for the measurement of burnout with internal consistency reliability ranging from .84 to .90 for $\mathrm{EX}, .74$ to .78 for $\mathrm{CY}$, and .70 to 78 for PE (Maslach et al., 1996).

\section{Stress of Conscience}

Stress of conscience was measured using the SCQ. Glasberg et al. (2006) were the first to develop an instrument measuring conscience, based on the feelings of guilt and shame, for HCWs. The SCQ is a nine-item instrument scored on two dimensions: internal 
demands and external demands and restrictions. Internal demands are defined as the HCWs perceptions being forced to provide care, and external demands and restrictions is defined as conflicts with personal conscience (Glasberg et al., 2006). Each item is a question that evaluates the frequency of a stressful occurrence using a Likert-type scale ranging from 1 ("almost always") to 6 ("almost never"). Each question is repeated to evaluate the extent of perceived degree of troubled conscience (defined as conflicts related to one's basic values and sense of what is right and wrong) using a Likert scale ranging from 0 ("No, not at all") to 5 ("Yes, it gives me a very troubled conscience"). The SCQ has shown to be a reliable and valid instrument for the measurement of stress of conscience in HCWs with external Cronbach's alpha between 0.33 and 0.66 and internal Cronbach's alpha of 0.83 , indicating concordance among all items (Glasberg et al., 2006).

\section{Spiritual Wellbeing}

For this study, existential spiritual wellbeing was measured using the general nonillness version of FACIT-SP that contains 12 items rated on a 5-point Likert-type scale (Peterman et al., 2002). Each item response ranges from 0 ("not at all") to 4 ("very much") with higher scores indicating more spiritual wellbeing. This instrument contains two subscales whose combination produces a total score of spiritual wellbeing: "Meaning/Peace," with eight items measuring the meaning and purpose in life, and "Faith/Assurance," with four items measuring the degree of spiritual belief. Peterman et al. (2002) determined that the FACIT-SP is a reliable and valid instrument to measure quality of life and subjective spiritual wellbeing. The reported overall internal consistency of Cronbach's alpha is 0.87 and the two subscales' internal consistency of Cronbach's alpha were 0.81 and 0.88 respectively. 


\section{Mindfulness}

This study measured mindfulness on scores using the MAAS (Brown \& Ryan, 2003), a 15-item self-report instrument that measures the presence or absence of attention and awareness to events occurring at the present time. Respondents rank the frequency of attention and awareness experienced during everyday activities using a Likert-type scale ranging from 1 ("almost always") to 6 ("almost never"). A mean score is obtained and

results range from 15-90. Higher scores indicate higher levels of mindfulness and internal consistency is reported of Cronbach's alpha of 0.84 (Brown \& Ryan, 2003).

\section{Data Collection}

\section{Instruments}

Data collection of the instruments is illustrated in Table 2. 
Table 2

Measures

\begin{tabular}{l|l|l|l}
\hline \multicolumn{4}{|c}{ Outcome Variables } \\
\hline Construct & Instrument & Description & Cronbach's Alpha \\
\hline Burnout & MBI-GS & Likert-type scale & \\
\hline Conscience & SCQ & 9 items, 5-6 point & .83 \\
\hline Existential & FACIT-SP & Likert-type scale & \\
Spiritual & & Likert-type scale & \\
Wellbeing & & & .88 to.90 \\
\hline Mindfulness & MAAS & 15 items, 6 point & .87 \\
\hline $\begin{array}{l}\text { Professional Data } \\
\text { Demographic and }\end{array}$ & & Likert-scale & \\
\hline
\end{tabular}

\section{Procedures}

Participants who enrolled in the MRP were given a uniform resource locator (URL) as a standardized way to access a secure website to complete the survey questionnaires. The online system provided participants anonymity by blocking identification of IP addresses, URLs, and email addresses. The online system meets Federal guidelines for website accessibility and is Section 508 compliant by meeting accessibility to people with disabilities. 
Data were collected from March 2012 to August 2012 at three intervals via online surveys upon course enrollment, after the last class session, and three months later. Periodic class and survey reminders were emailed to the participants.

Table 3

Data Collection Time-Points

\begin{tabular}{|c|c|c|c|c|}
\hline Measure & $\begin{array}{l}\text { Course } \\
\text { Enrollment }\end{array}$ & Week 1 & $\begin{array}{c}\text { Week } 12 \\
\text { (After } \\
\text { Session 6) }\end{array}$ & $\begin{array}{c}\text { Week } 24 \\
(3 \text { months } \\
\text { after } \\
\text { Session } 6 \\
\text { Follow-Up) }\end{array}$ \\
\hline Implied Informed Consent & $X$ & & & \\
\hline Demographic Data & & $\mathrm{X}$ & & \\
\hline Burnout & & $X$ & $X$ & $X$ \\
\hline Stress of Conscience & & $\mathrm{X}$ & $X$ & $\mathrm{X}$ \\
\hline Spiritual Wellbeing & & $\mathrm{X}$ & $\mathrm{X}$ & $x$ \\
\hline Mindfulness & & $x$ & $\mathrm{X}$ & $\mathrm{X}$ \\
\hline Mantram Practice Questions & & & $x$ & $X$ \\
\hline
\end{tabular}

\section{Data Management and Analysis}

The data were analyzed using Statistical Package for the Social Sciences (SPSS) version 20. Prior to analysis, the researcher and an associate conducted a preliminary 
review of the data to become familiar with the variables and check for inaccuracies. Entries were examined for random or patterned missing data and coded. Descriptive results were reported on all dependent and independent variables to examine distributions.

The first research question concerned the relevant demographic and professional characteristics of a group of HCWs participating in a structured internet-delivered MRP. Descriptive characteristics of the participants were analyzed. To answer the second research question, analyses of variances (ANOVAs) were used to analyze the participants' levels of burnout subscales, stress of conscience, spiritual wellbeing and mindfulness at baseline, post-intervention and three months following participation. For the third research question, ANOVAs were used to determine differences of change over time of burnout subscales, stress of conscience, spiritual wellbeing, and mindfulness was related to participants' demographic and professional characteristics. Internal consistency reliability for each instrument, including subscales, was calculated using Cronbach's alpha.

\section{Strengths and Limitations}

There may be several limitations to this study. The sample was limited to HCWs employed by the VA Healthcare System and therefore is not generalizable to those at private or other public agencies. VA HCWs are a small percentage compared to the HCW population in general. In addition, the non-response rate of all enrolled in the MRP program could influence the results if the non-responders were significantly different from those that responded. Findings from this study may not have generalizability to the broader population. Another limitation is not having a control group; however, this study was the first of its kind and was designed as an efficacy, not effectiveness study. 
A study strength is the innovative nature of the intervention, through which findings may be used to assess if there are relationships between a structured internetdelivered MRP and burnout, stress of conscience, spiritual wellbeing, and mindfulness. There are low potential physical, psychological, or social risks to the subjects due to the secondary analysis.

\section{Summary}

The purpose of this study was to examine the efficacy of an MRP on HCWs' selfreported behavioral outcomes, including subscales of burnout, stress of conscience, spiritual wellbeing and mindfulness. The data analyses were appropriate for the data set, study purpose, and design. Results of this study may contribute to the literature by providing new knowledge about self-initated interventions and effects of a structured internet-delivered MRP. 


\section{CHAPTER IV}

\section{RESULTS}

The purpose of this research was to examine the relationship between a structured internet-delivered MRP and several outcome factors. The specific aims of this study were to 1) describe relevant demographic and professional characteristics in a group of HCWs participating in the MRP; 2) describe levels of burnout, stress of conscience, spiritual wellbeing, and mindfulness in a group of $\mathrm{HCWs}$ at baseline, post-intervention, and three months following participation; and 3) determine if significant differences exist across relevant demographic and professional characteristics in levels of burnout, stress of conscience, spiritual wellbeing, and mindfulness at baseline, post-intervention and three months after participation in the MRP.

The results of the analysis are presented in three sections. The first section describes the characteristics of the participants. The second section presents the analysis of the levels of burnout subscales, stress of conscience, spiritual wellbeing, and mindfulness at baseline, post-intervention, and three-month follow-up. The third section presents the analysis of differences in the levels between time-points across relevant demographic and professional characteristics. 


\section{Participant Characteristics}

This study conducted an evaluation of the efficacy of an internet-delivered stress management course in a self-selected group of HCWs using five surveys. The first survey gathered information about the participants' general demographic and professional characteristics such as education, role, and experience in healthcare. The variables were selected to access and control for their confounding potential.

To answer the first research question, the participants' characteristics were analyzed using descriptive statistics. In a repeated measures analysis, equal correlations were used, meaning if one time-point was missing the subject was dropped from the data set. Of the 54 participants who consented to be part of the study and completed the

pretest survey, 39 (72\%) completed the MBI-GS, 35 (65\%) completed the SCQ, and 38 (70\%) completed the FACIT-12 and MAAS at all time-points. These responses were used for data analyses.

The majority of participants ( $87 \%$ ) were female. The mean age of participants was 51 years $(\mathrm{SD}=8.6)$ and ranged from 27 to 67 years. The majority of HCWs (76\%) had direct patient contact. RNs made up the largest category (39\%) of healthcare roles. Time in the current position ranged from 1 to 25 years with a mean of 6.54 years $(\mathrm{SD}=6.53)$. The mean number of years with the current VA employer was 10.67 $(S D=9.28)$ and ranged from 1 to 40 years. The mean number of years within the healthcare profession was $21.59(\mathrm{SD}=10.13)$, ranging from 1 to 41 years.

With respect to current attitudes about spiritual wellbeing and religious factors, participants identified the importance of spirituality and religion as "very important" 
$(64 \%)$ or "somewhat important" $(36 \%)$. The majority of participants $(59 \%)$ practiced other types of meditation or mindfulness at baseline.

Table 4

Demographic Data $(n=39)$

\begin{tabular}{lccc}
\hline Variable & $X(\mathrm{SD})$ & Range & Frequency \\
\hline Age & $51.21(8.6)$ & $27-67$ & \\
\hline Years & & \\
Current Position & $6.54(6.53)$ & $1-25$ & \\
Current Employer & $10.67(9.28)$ & $1-40$ & \\
Healthcare & $21.59(10.13)$ & $1-41$ & \\
\hline Gender & & $34(87 \%)$ \\
Female & & $5(13 \%)$ \\
Male & & $5(13 \%)$ \\
\hline Race & & $25(64 \%)$ \\
White & & $2(5 \%)$ \\
Asian & & $2(5 \%)$ \\
Other & & $5(13 \%)$ \\
\hline Marital Status & & \\
Single & & \\
Married/partnered & & \\
\hline Separated divorced & & \\
\hline Oducation & & \\
\hline
\end{tabular}




\begin{tabular}{lc}
\hline Masters & $25(64 \%)$ \\
Doctorate/PhD & $6(15 \%)$ \\
\hline Current Role & $5(13 \%)$ \\
Psychologists & $7(18 \%)$ \\
Social Workers & $12(31 \%)$ \\
Other Healthcare & $15(38 \%)$ \\
RN/APRNs & \\
\hline Direct Patient Contact & $9(23 \%)$ \\
No & $30(77 \%)$ \\
Yes & $16(41 \%)$ \\
\hline Work Week & $23(59 \%)$ \\
\hline 39 hours/week & $1(3 \%)$ \\
\hline 40 hours/week & $38(97 \%)$ \\
\hline Importance of spiritual/religiou & $25(64 \%)$ \\
\hline Very important & $14(36 \%)$ \\
\hline Practice other types of & \\
\hline
\end{tabular}

Mean scores at baseline, post-course, and three-month follow-up for each instrument was conducted. Descriptive statistics were performed at each time-point. 


\section{Analysis of Levels}

\section{Burnout}

Authors of the MBI-GS suggest that subscale scores not be combined into an overall score but reported as individual subscale scores (Maslach \& Jackson, 1996) based on factor analyses and psychometric findings in a variety of populations. For this reason, it should be noted that separate analyses of MBI subscales were done for this study. Higher levels of burnout correspond with higher scores on the EX and CY subscales. PE is scored in the opposite direction with low scores corresponding with higher levels of burnout. These relationships were supported in this study.

The mean scores at baseline, post-course and three-month follow-up for each of the three MBI-GS subscales are represented in Table 5.

Table 5

Maslach Burnout Inventory-General Survev Scores

\begin{tabular}{|c|c|c|c|c|c|c|c|c|c|c|}
\hline & $\mathrm{X}(\mathrm{SD})$ & $\begin{array}{r}F \\
(d)\end{array}$ & p & $\begin{array}{l}\text { Effect } \\
\text { Size } \\
\eta p 2\end{array}$ & $\begin{array}{c}F \\
(d f) \\
\text { Linear }\end{array}$ & $\mathrm{P}$ & $\begin{array}{c}\text { Effect } \\
\text { Size } \\
\text { ๆp2 }\end{array}$ & $\begin{array}{c}F \\
(d f) \\
\text { Quadratic }\end{array}$ & $\mathbf{P}$ & $\begin{array}{l}\text { Effect } \\
\text { Size } \\
\eta p 2\end{array}$ \\
\hline \multicolumn{11}{|l|}{ Exhaustion } \\
\hline Time 1 & $4.08(1.22)$ & $3.39(2)$ & .039 & .082 & $4.98(1)$ & .032 & .116 & $.849(1)$ & .363 & .022 \\
\hline Time 2 & $3.97(1.39)$ & & & & & & & & & \\
\hline Time 3 & $3.56(1.54)$ & & & & & & & & & \\
\hline \multicolumn{11}{|l|}{ Cynicism } \\
\hline Time 1 & $2.51(1.25)$ & $1.31(2)$ & .276 & .033 & $.368(1)$ & .547 & .010 & $3.18(1)$ & .086 & .076 \\
\hline Time 2 & $2.81(1.48)$ & & & & & & & & & \\
\hline Time 3 & $2.64(1.43)$ & & & & & & & & & \\
\hline \multicolumn{11}{|c|}{ Professional } \\
\hline \multicolumn{11}{|l|}{ Efficacy } \\
\hline Time 1 & $6.19(.68)$ & $2.68(2)$ & .075 & .066 & $.001(1)$ & .974 & .000 & $6.54(1)$ & .015 & .147 \\
\hline Time 2 & $6.43(.49)$ & & & & & & & & & \\
\hline Time 3 & $6.19(.73)$ & & & & & & & & & \\
\hline
\end{tabular}


There was a statistically significant linear effect of the MRP showing a decrease in the MBI-GS exhaustion subscale across the three time-points $[\mathrm{F}(2,76)=3.93, \mathrm{p}<.039]$ and a significant quadratic effect for the professional efficacy subscale showing an initial increase at post-course followed by a decrease at 3-month follow-up $[\mathrm{F}(1,38)=6.54$, $\mathrm{p}<.02]$. No significant changes were found for the cynicism subscale.

\section{Stress of Conscience}

Stress of conscience is defined as those conflicts that occur in relation to one's basic values and views of what is right or wrong and provoke feelings of guilt and shame for HCWs (Glasberg et al., 2006). The SCQ was used in this study to evaluate stress of conscience. A nine-item instrument was scored on two dimensions: internal demands (the frequency of being forced to provide care) and external demands and restrictions (the extent of an HCW's personal or troubled conscience; Glasberg et al., 2006).

No patterns emerged in the evaluation of SCQ individual items and no significant changes emerged in the total scores of internal and external demands over time. However, evaluating the subscales independently did reveal statistical significance. Internal demands, measuring the frequency of troubled conscience, had a quadratic effect $[F(1,34)$ $=5.23, \mathrm{p}<.03]$ over time showing a continued decrease at the three-month follow-up. The SCQ subscale external demand, the evaluation of extent of troubled conscience, had a linear change over time showing an improvement at the post-course time-point $[F(1,34)=$ $4.71, \mathrm{p}<.03]$. 
Table 6

Stress of Conscience Scores

\begin{tabular}{|c|c|c|c|c|c|c|c|c|c|c|}
\hline & $X(\mathrm{SD})$ & $\begin{array}{l}\text { I } \\
\text { (d) }\end{array}$ & $\mathbf{p}$ & $\begin{array}{l}\text { Effect } \\
\text { Size } \\
\text { ир2 }\end{array}$ & $\begin{array}{c}\mathrm{F} \\
(\mathrm{d}) \\
\text { Linear }\end{array}$ & $\mathrm{P}$ & $\begin{array}{c}\text { Effect } \\
\text { Size } \\
n p 2\end{array}$ & $\begin{array}{c}\text { F } \\
\text { (dr) } \\
\text { Quadratic }\end{array}$ & $\mathrm{P}$ & $\begin{array}{r}\text { Effect } \\
\text { Size } \\
\eta p 2\end{array}$ \\
\hline \multicolumn{11}{|l|}{$\overline{\text { Total }}$} \\
\hline Time 1 & $26.23(20.30)$ & $1.55(2)$ & .219 & .044 & $2.01(1)$ & .166 & .056 & $.741(1)$ & 396 & .021 \\
\hline Time 2 & $21.63(19.96)$ & & & & & & & & & \\
\hline Time 3 & $21.09(20.86)$ & & & & & & & & & \\
\hline \multicolumn{11}{|c|}{ Internal Demands } \\
\hline \multicolumn{11}{|l|}{ Time 1} \\
\hline Time 2 & $13.76(6.98)$ & $4.81(2)$ & .011 & .115 & $4.48(1)$ & .041 & .108 & $5.23(1)$ & .028 & .124 \\
\hline \multirow[t]{2}{*}{ Time 3} & $10.73(6.76)$ & & & & & & & & & \\
\hline & $11.47(7.54)$ & & & & & & & & & \\
\hline \multicolumn{11}{|c|}{ External Demands } \\
\hline \multicolumn{11}{|l|}{ Time 1} \\
\hline Time 2 & $12.95(9.35)$ & $2.57(2)$ & .083 & .067 & $4.71(1)$ & .037 & .116 & $.017(1)$ & .898 & .000 \\
\hline \multirow[t]{2}{*}{ Time 3} & $11.38(9.93)$ & & & & & & & & & \\
\hline & $10.08(8.30)$ & & & & & & & & & \\
\hline
\end{tabular}

\section{Spiritual Wellbeing}

Spiritual wellbeing was measured using the general non-illness version of FACITSP that contains 12 items rated on a five-point Likert-type scale (Peterman et al., 2002). This instrument contains two subscales: "Meaning/Peace," with eight items measuring the meaning and purpose in life, and "Faith/Assurance," with four items measuring the relationship of spiritual and/or religious belief. A total score of spiritual wellbeing is produced but based on other factor analyses, scores of the Meaning/Peace subscale were also analyzed individually.

The total mean score at baseline, post-course, and three-month follow-up for FACIT-12 is represented in Table 7 . There was a statistically significant effect of the 
MRP showing an increase in the total FACIT-SP scores across the three time-points $[F(2,37)=11.76, p<001)$ with quadratic effect increases in both subscales. The Meaning/Peace subscale had a quadratic $[F(2,37)=16.34, p<.000]$ effect across the three time-points and the Faith/Assurance subscale had a quadratic effect across the three timepoints $[F(2,37)=8.41, p<.006]$.

Table 7

Functional Assessment of Chronic Illness Therapy Spirittal Wellbeing Scale Scores

\begin{tabular}{|c|c|c|c|c|c|c|c|c|c|}
\hline & $\bar{\lambda}(\mathrm{SD})$ & $\begin{array}{c}F \\
(\mathrm{df})\end{array}$ & $p$ & $\begin{array}{l}\text { Effect } \\
\text { Size } \\
\eta p 2\end{array}$ & $\begin{array}{c}F \\
\text { (df) } \\
\text { Linear }\end{array}$ & $\mathrm{P}$ & $\begin{array}{c}\text { Effect } \\
\text { Size } \\
\eta p 2\end{array}$ & $\begin{array}{c}\text { F } \\
\text { (df) } \\
\text { Quadratic }\end{array}$ & $\begin{array}{l}\text { P Effec } \\
\text { Size } \\
\eta p 2\end{array}$ \\
\hline \multicolumn{10}{|l|}{ Total } \\
\hline Time 1 & $32.01(9.23)$ & $11.76(2)$ & .000 & .241 & $6.54(1)$ & .015 & .150 & $20.18(1)$ & .000 .353 \\
\hline Time 2 & $37.16(6.93)$ & & & & & & & & \\
\hline Time 3 & $35.08(7.66)$ & & & & & & & & \\
\hline \multicolumn{10}{|c|}{ Meaning and Peace } \\
\hline Time 1 & $23.11(5.46)$ & $10.66(2)$ & .000 & .224 & $7.26(1)$ & .011 & .164 & $16.34(1)$ & .000 .310 \\
\hline Time 2 & $26.62(3.74)$ & & & & & & & & \\
\hline Time 3 & $25.47(4.18)$ & & & & & & & & \\
\hline \multicolumn{10}{|c|}{ Faith and Assurance } \\
\hline Time 1 & $9.00(4.81)$ & $4.90(2)$ & .019 & .102 & $1.22(1)$ & .296 & .029 & $8.41(1)$ & .006 .185 \\
\hline Time 2 & $10.53(4.39)$ & & & & & & & & \\
\hline Time 3 & $9.60(4.38)$ & & & & & & & & \\
\hline
\end{tabular}

\section{Mindfulness}

This study measured mindfulness of everyday activities. Scores on the MAAS indicate the presence or absence of attention and awareness to events occurring at the present time. There was a statistically significant effect of the MRP showing an increase in the total MAAS scores across the three time-points $[F(2,33)=18.19, p<000)]$. 
Table 8

Mindfulness Awareness Attention Scale Scores

\begin{tabular}{|c|c|c|c|c|c|c|c|c|c|c|}
\hline & $X(S D)$ & $\begin{array}{c}\mathrm{F} \\
\mathrm{d}(\mathrm{d})\end{array}$ & $p$ & 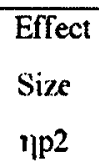 & $\begin{array}{c}F \\
(d f) \\
\text { Linear }\end{array}$ & $\bar{P}$ & $\begin{array}{c}\text { Effect } \\
\text { Size } \\
\eta p 2\end{array}$ & $\begin{array}{c}\text { F } \\
\text { (df) } \\
\text { Quadratic }\end{array}$ & $\mathrm{P}$ & $\begin{array}{r}\text { Effect } \\
\text { Size } \\
\eta p 2\end{array}$ \\
\hline Time 1 & $55.38(12.66)$ & $18.19(2)$ & .000 & .355 & $17.51(1)$ & .000 & .347 & $19.68(1)$ & .000 & .374 \\
\hline Time 2 & $64.79(11.10)$ & & & & & & & & & \\
\hline Time 3 & $63.79(9.92)$ & & & & & & & & & \\
\hline
\end{tabular}

\section{Analysis of Differences}

The third section presents the analysis of significant differences in the levels between the time-points across relevant demographic and professional characteristics. An evaluation of the relationship between burnout, stress of conscience, spiritual wellbeing, and mindfulness and potential covariates (all demographic and professional characteristics) at baseline and relationship among the scales over time was conducted. None of the covariates examined were significantly related to the scales at any of the three time-points. Possible interaction effects among covariates as they related to the scales changes over time were evaluated using 2 (group: e.g., gender, above/below median age) by 3 (time) mixed-design ANOVAs. No significant group-by-time interaction effects were noted. Hence, covariates did not account for the outcomes.

\section{Analysis of Measurements}

The internal consistency reliability of the measures used in this study was determined using Cronbach's alpha. The MBI-GS scale consisted of 16 items, the MBIGS the exhaustion subscale consisted of 5 items $(\alpha=.88)$, the MBI-GS cynicism subscale consisted of 5 items ( $\alpha=84)$, and the MBI-GS professional efficacy consisted of 6 items 
$(\alpha=.68)$. The SCQ total score consisted of 18 items ( $\alpha=.88)$, the SCQ internal demands consisted of 9 items $(\alpha=.79)$, and the SCQ external demands and restrictions consisted of 9 items $(\alpha=92)$. The FACIT-12 total score consisted of 12 items $(\alpha=.81)$, the Meaning/Peace consisted of 8 items $(\alpha=.54)$, and the Faith/Assurance consisted of 4 items $(\alpha=.90)$. The 15 -item MAAS scored as a total mean score $(\alpha=.89)$.

\section{Summary}

This chapter presented the data analysis results in three sections based on the specific aims of the study. An assessment of internal consistency reliability for each instrument utilized in the study was reported. There were statistically significant associations between MRP and two subscales of burnout, (exhaustion and professional efficacy), stress of conscience subscales, spiritual wellbeing subscales, and mindfulness. 


\section{CHAPTER V}

\section{DISCUSSION AND CONCLUSION}

This chapter includes a summary of the research design and method, discussion of research findings, implications for nursing science including a proposed research trajectory, and the study conclusion.

\section{Summary of the Research Design and Method}

The purpose of this study was to examine the efficacy of MRP on HCWs' selfreported behavioral outcomes, including burnout, stress of conscience, spiritual wellbeing and mindfulness. The conceptual framework for the study was based on Lazarus and Folkman's (1984) transactional model of stress and coping. For this study, participants enrolled in an educational program of skills training available to HCWs of a selected healthcare system. The program was composed of six 50-minute classes offered biweekly over a three-month period. Three primary stress reduction strategies defined as mantram repetition, slowing down, and one-pointed attention were taught. Participants completed several online assessments at baseline, post-course and three months after participation in the MRP, including demographic and professional characteristics, Maslach Burnout Inventory-General Survey (MBI-GS), Stress of Conscience (SCQ), Functional Assessment of Chronic Illness Therapy Spiritual Wellbeing Scale-12 items (FACIT-12) 
and the Mindfulness Attention Awareness Scale (MAAS).

The following research questions were addressed:

1. What are the relevant demographic and professional characteristics in a group of HCWs participating in a structured internet-delivered MRP?

2. What are the levels of burnout, stress of conscience, spiritual wellbeing, and mindfulness in a group of HCWs at baseline, post-intervention, and three months following participation in a structured internet-delivered MRP?

3. Do significant differences exist across relevant demographic and professional characteristics in levels of burnout, stress of conscience, spiritual wellbeing, and mindfulness at baseline, post-intervention, and three months after participation in a structured internet-delivered MRP?

Data were analyzed using SPSS version 20. Descriptive and inferential statistics were conducted to examine the relationships between the study variables of burnout, stress of conscience, spiritual wellbeing and mindfulness. The results of the study supported that the internet-delivered MRP diminished two subcales of burnout and stress of conscience and improved spiritual wellbeing and mindfulness.

\section{Summary and Discussion of Research Findings}

\section{Research Question 1}

The original study data set was derived from a convenience sample of HCWs enrolled in the MRP. Data were collected at baseline, immediately after the intervention, and three months post-intervention. The study was conducted within a national healthcare system with $125 \mathrm{HCWs}$ voluntarily enrolled in the MRP series. Of these, 54 participants completed the first survey and enrolled in the original study. 
Demographic and professional characteristics were completed in the first survey, but only 39 participants continued in the study by completing the MBI-GS, 35 completed the SCQ, and 38 completed the FACIT-12 and MAAS at all time-points. For this study, data analysis was completed on the data set of 39. It is important to note all participants within this data set did not complete the SCQ survey. This response rate is acceptable as the SCQ is most appropriate for HCWs who have direct patient contact. The majority of participants $(76 \%)$ did report having direct patient contact. No rationale is available for the study participant who did not complete the FACIT-12 and MAAS survey at the third time-point.

The participants' demographic and professional characteristics were analyzed using descriptive statistics. The sample consisted of 5 males (13\%) and 34 females (87\%). In addition to being primarily female, the participants in the sample were overwhelmingly White (90\%), married/partnered (64\%), and working 40 hours or more per week (97\%). The majority of participants (92\%) were also highly educated, with $13 \%$ having a bachelors degree, $64 \%$ having a masters degree, and $15 \%$ having a doctoral degree. The participants' ages ranged from 27 years to 67 years, with a mean of 51 years. RNs made up the largest category (39\%) of healthcare roles in this study. This is not an extraordinary finding as the United States Bureau of Labor Statistics represents RNs are the largest healthcare occupation, reported as 2.7 million (BLS, 2010).

The demographic and professional characteristics of this sample closely match the average U.S. worker with the exception of position tenure. Participants in this study reported a mean of 10.67 years in the current employer, with a range from 1 to 40 years. According to the United States Bureau of Labor Statistics, the median employee tenure 
for workers is 4.6 years, but when accounting for age differences, median tenure with a current employer is 3.2 years for those aged 25 to 34 and 10 years for those 55 or older (BLS, 2012). The participants in this study reported a higher tenure than the average US employee.

With respect to current attitudes related to spiritual/wellbeing and religious factors, participants identified spirituality and religion as "very important" (64\%) or "somewhat important" $(36 \%)$. The majority of participants (59\%) practiced other types of meditation or mindfulness at baseline. These finding are consistent with consideration of the participants as self-selected into the study, and therefore, interested in the mind-bodyspiritual interventions within MRP.

\section{Research Question 2}

A repeated measures prospective design was used to evaluate the effectiveness of the MRP. The MRP was implemented from March 2012 to June 2012. To answer the second research question, ANOVAs were used to analyze the participants' levels of burnout, stress of conscience, spiritual wellbeing and mindfulness at baseline, postintervention and three months following participation.

For this study, burnout was measured using the Maslach Burnout InventoryGeneral Survey (MBI-GS) by Schaufeli, Leiter, Maslach, and Jackson (1996). Internal consistency reliability was within expectations with the EX subscale Cronbach's alpha score of .88 , the CY subscale Cronbach's alpha score of .84 , and the PE subscale Cronbach's alpha score of as .68. Findings in this study showed statistically significant effects of the MRP with a decrease in the MBI-GS exhaustion subscale across the three 
time-points $[F(2,76)=3.93, p=.039]$ and a quadratic effect for professional efficacy subscale showing an initial increase followed by a decrease $[F(1,38)=6.54, p<.02]$.

In this sample of HCWs, no statistically significant differences in cynicism subscale post MRP throughout the time-points was noted. An explanation for the findings in this research may be explained by exploring the linear relationships of the burnout antecedents. The exhaustion subscale is noted as the most strongly connected antecedent of burnout and the predecessor of professional efficacy, followed by cynicism (Maslach et al., 1996). Cynicism may not have reached a significant threshold due to the statistical significant improvements in the other burnout subscales. Another explanation for the lack of significant change in the cynicism subscale may be related to the significant changes in the other variables; stress of conscience, spiritual wellbeing, and mindfulness.

Evidence of the effects of MRP, reported in this study as improving the antecedents of burnout in a group of HCWs, was consistent with previous research (Cohen et al., 2005; Günüşen \& Üstün, 2010; Mackenzie et al., 2006; Oman et al., 2006; Rowe, 1999; Shapiro et al., 2005; and Yong et al., 2011) that reported statistical significance following implementation of spiritual-based programs in HCWs.

Findings to support the use of MRP to reduce the antecedents of burnout are an important discovery, as portable interventions are needed to improve the psychological wellbeing of $\mathrm{HCWs}$ that produce sustained results over time. The improvements in burnout subscales in this study supports the continued use and dissemination of a MRP as an intervention for improving the self-reported behavioral outcomes in HCWs.

Stress of Conscience was evaluated using the SCQ, a nine-item instrument scored on the dimensions of internal demands and external demands and restrictions. Although 
SCQ mean scores decreased over time, there was no statistical significance of combined scores. When subscales were analyzed separately, SCQ internal demand subscale had a quadratic effect $[F(1,34)=5.23, p<.03]$ over time showing a decrease at the three-month follow-up. The SCQ subscale external demand had a linear effect $[F(1,34)=4.71, p<.04]$ immediately after the intervention. While mean scores continued in a downward trend, at the three-month follow-up there was no significance noted.

These results suggest that the MRP positively influences the stress of conscience subscales, internal and external demands. Specifically, after MRP participation results suggest HCWs perceive a decrease in frequency and extend of troubled conscience over time. This is an important finding as the frequency and extent of one's troubled conscience may lead to the antecedents of burnout, including increased exhaustion and cynicism, and decreased professional efficacy. The burden of increased troubled conscience may also contribute to job dissatisfaction, absenteeism and turnover.

While the direct relationship of these findings with MRP interventions is not clear it is suggested the three primary stress reduction strategies from MRP are useful in decreasing frequency and extent of the troubled conscience of HCWs. Of note, the notion of how one is and acts is guided by conscience yet internal demands, the frequency of experiencing stress of conscience, may to some extent be set by current workloads and conditions versus under the direct control of the $\mathrm{HCW}$.

The reliability (internal consistency) of the SCQ in this study was within acceptable limits with an overall SCQ combined Cronbach's alpha score of .88, the SCQ internal demand subscale Cronbach's alpha score of .79, and the SCQ external demand 
subscale Cronbach's alpha score of .92 were in concordance with reported reliability in the literature (Glasberg et al., 2006).

Subjective spiritual wellbeing was measured using the FACIT-12, a twelve-item instrument scored on the dimensions of Meaning/Peace and Faith/Assurance. There was a statistically significant effect increasing the total FACIT-SP scores across the three timepoints $[F(2,37)=11.76, p<001]$. The Meaning/Peace subscale had a quadratic $[F(2,37)$ $=16.34, p<.000]$ effect across the three time-points and the Faith/Assurance subscale had a quadratic effect across the three time-points $[\mathrm{F}(2,37)=8.41, \mathrm{p}<.006]$, both initially increased followed by a decrease over time.

This research study found that MRP participants increased spiritual wellbeing in HCWs. The feelings of Meaning/Peace and Faith/Assurance may help to reduce stress reactions, which can lead to burnout and stress of conscience. The improvement in spiritual wellbeing may promote a healthier psychological outlook for the HCW. A synergistic relationship may account for the increase in mindfulness and spiritual wellbeing after participation in MRP. Given that HCWs experience a higher incidence of substance abuse, suicide, depression and anxiety (NIOSH, 2008), a healthier psychological state may prevent or alleviate stress and burnout.

Mindfulness was measured using the MAAS to evaluate if the interventions taught (specifically, one-pointed attention and slowing down) had measureable outcomes on the participants. There was a statistically significant effect in the total MAAS scores across the three time-points $[F(2,33)=18.19, p<000]$ after participation in MRP. This research study found that MRP is an effective mechanism to help HCWs increase their 
mindfulness. The increase in mindfulness post-MRP is supported by similar research findings using self-initiated stress reduction training (Cohen-Katz et al., 2005).

All analyses demonstrated significant improvements on the MAAS scores. This study found that MRP successfully increased mindfulness and may enhance practice, by decreasing burnout and stress of conscience and improving spiritual wellbeing. The robust increase of mindfulness of HCWs was reinforced and supported throughout the MRP interventions. The concepts of mindfulness and MRP interventions are similar and may have a synergistic relationship with the other variables. The possibility that MRP interventions support the mindfulness of HCWs may lend support for a safer work situation and higher quality of care.

Brown and Ryan (2003) determined that the MAAS is a reliable and valid instrument with reported overall internal consistency of Cronbach's alpha score of 0.83 . In this study, the MAAS internal consistency of Cronbach's alpha score of .89 was congruent with previous findings.

\section{Research Question 3}

For the third research question, ANOVAs were used to determine differences whether the patterns of change over time of burnout, stress of conscience, spiritual wellbeing, and mindfulness were related to participants' demographic and professional characteristics. Assessment of the effectiveness of the MRP is more sensitive in repeatmeasures designs because demographic and professional characteristics could influence the measured outcomes. Relationships between covariates could influence the results among scales over time and therefore the lack of interaction effects is a finding that supports that the study findings were the result of the MRP. In this study, it was 
determined that the covariates did not account for the study outcomes and learning effects occurred each time participants responded.

While interpreting the results, study strengths must be considered against study limitations. The sample size for this study was powered at $92 \%$ and revealed statistically meaningful results. Another strength is the high retention rate (72\%) of participants over the six-month study period.

Although this study found statistically significant results consistent with prior research studies, there are some limitations. The study design did not include a control group or randomization of participants. The study sample was adequately powered but all participants were employed in one national healthcare system. Another possible limitation is that a single instructor, a known expert in MRPs, taught the internetdelivered MRP. Instructors who are not content experts in MRP might not necessarily reproduce the same results.

It was not within the scope of this research study to analyze the demographic and professional characteristics or other variables among all participants who originally consented to the MRP study. Further analysis of the original data set may warrant future contact with HCWs who chose not to continue study participation to explore differences between participants who completed the study. If the subset of participants were found to have higher scores of burnout and stress of conscience, it may be important to explore potential barriers in MRP participation. Evaluating the ease of obtaining and using selfinitiated tools to improve psychological wellbeing for all $\mathrm{HCWs}$ may provide insight to implementing future course offerings. 
This study had significant findings of MRP efficacy in reducing exhaustion and improving professional efficacy, elements of burnout, stress of conscience subscales, spiritual wellbeing subscales, and mindfulness in a group of HCWs. Though a threemonth follow-up was in the purview of this study, it is unknown if these constructs would have remained over an extended time and continued to assist HCWs.

\section{Implications for Nursing Science}

The study findings present multiple implications for nursing research. In summary, the results of this study were consistent with previous mantram repetition studies in HCWs. MRP demonstrated positive psychosocial and spiritual wellbeing effects for participants who used and continued the learned techniques over time. Findings suggest that participation in a MRP can effectively improve dimensions of burnout and stress of conscience while improving spiritual wellbeing and mindfulness in a group of HCWs. The findings have implications for refining the implementation of the MRP by expanding the offerings to HCWs to lessen burnout rates and stress of conscience. Reducing burnout rates and stress of conscience may be an effective strategy for improving $\mathrm{HCW}$ wellbeing and could improve the $\mathrm{HCW}$ shortage. The findings provide support that the MRP is useful for managing stress and improving wellbeing.

This study contributes to the current understanding of the efficacy of MRPs and supports the utility of MRPs for stress management in decreasing burnout and stress of conscience in HCWs. The findings will be of interest to those seeking innovative, portable methods to improve spiritual wellbeing and mindfulness amongst healthcare workers. Additional controlled longitudinal research is warranted to explore the potential to improve patient safety and outcomes by decreasing burnout in HCWs. 
Additional research is needed to determine if continued contact and course offerings with MRP participants enhances learned techniques that contributed to the significant outcomes of this study. Additional follow-up programs to reinforce MRP interventions to support practice may be needed to sustain outcomes over extended periods of time. Given that the intervention used innovative technology to deliver the MRP, continued support could be live peer-led groups or internet-based focus groups. For this study, MRP course objectives included three of Easwaran's Eight Point Program, however, future course offerings could review previously taught interventions and introduce the remaining tenets of Easwaran's Eight Point Program.

To strengthen the ability the generalizability of the results, future studies are needed with a larger, more diverse population to determine the relationship of MRP and self-reported behavioral outcomes on a longitudinal basis utilizing other MRP facilitators and include a comparison group. The non-response rate of all enrolled in the MRP program could influence the results if the non-responders were significantly different than those that responded. Findings from this study may not have generalizability to the broader population; therefore, further examination of the entire data set is warranted to determine if differences exist between demographic, professional, and self-described behavioral characteristics of participants who did and did not complete all three timepoint assessments.

In light of the increased national concern for safety and quality of care during hospitalizations, healthcare systems are tasked with improving patient outcomes and satisfaction while containing costs (McHugh et al., 2008; Kutney-Lee et al., 2009). Favorable resolutions of perceived stress are important to HCWs' wellbeing and may 
translate to improved patient care and safety. Research opportunities could evaluate objectives that healthcare administration view as key outcomes: employee satisfaction tools, staff turnover, overtime, patient event reports, hospital acquired infections, teambuilding, and healthy work environments. Administrative support is an important consideration since environmental work factors are known to negatively impact $\mathrm{HCW}$ burnout and negatively influencing patient outcomes (Aikens et al., 2002). Supporting the individual HCWs use of self-initiated strategies to improve psychological wellbeing coupled with organizational support directed to alleviate stressful work environments may improve employee wellbeing and patient outcomes.

The study relied on self-reported measures and a volunteer group may have intrinsic motivation and commitment to employ cognitive and behavioral changes. While this study used valid and reliable instruments to measure self-reported behavioral outcomes, future research using biomarkers could strengthen the results by controlling for objectivity. The comparison of this study's findings correlated with the analysis of future studies using biomarkers may enhance adoptability of the MRP.

Future implications may include the addition of MRP to pre-licensure nursing programs, new graduate residency programs, preceptor courses, and new employee orientation. Solutions to enhance work conditions are important to improving RN retention rates. The American Association of College of Nursing (AACN) describes factors contributing to decreased retention rates as high stress levels, decreasing job satisfaction, high turnover, and vacancy rates (AACN, 2008). Overall factors contributing to the $\mathrm{RN}$ shortage include shortage of nurse faculty, slow increase of $\mathrm{RN}$ population, increasing average age of RNs, and increased demand to care for an aging, higher acuity 
population (AACN, 2008). Challenges and potential solutions to alleviate job-related stress experienced by nurses are needed. Research that evaluates if MRPs positively impacts RNs could be helpful in alleviating the nursing shortage.

While empirical evidence from this study is moderate, a qualitative study is needed. A qualitative research design provides an excellent means of exploring the effects of the MRP on the experiences and consequences of HCWs over time. This is an important approach to gain an understanding in the ease and continued long-term use of MRP taught strategies. A qualitative design could lend toward representing the HCWs perception of environmental work events that trigger use of MRP tools. The following broad research questions could guide a future study: 1) What situations have occurred in your clinical environment that trigger use of strategies learned in the MRP? 2) How has practicing MRP strategies changed how you interact in your clinical setting? 3) What changes occurred in the way you perceive and react to stressful events within your clinical setting, if any? Depending on data analysis, more focused and directed questions could develop as the research evolves.

\section{Conclusion}

This analysis examined the efficacy of MRP on HCWs' self-reported behavioral outcomes, including burnout, stress of conscience, spiritual wellbeing, and mindfulness over a six-month period. There were statistically significant effects of the MRP found in the MBI-GS, SCQ, FACIT-12, and MAAS. Additional controlled longitudinal research is warranted. Little work has been done to explore the long-term effects of self-initiated programs for decreasing burnout and enhancing the wellbeing of HCWs, thus the current research findings have important implications regarding this potential intervention. 


\section{References}

Aiken, L., Clark, S., Sloane, D., Sochalski, J., Busse, R., Clake, H., Giovannetti, P.... Shamian, J. (2001). Nurses' reports on hospital care in five countries. Health Affairs, 20(3), 43-53.

Aiken, L., Clark, S., Sloane, D., Sochalski, J., \& Silber, J. (2002). Hospital nurse staffing and patient mortality, nurse burnout, and job dissatisfaction. $J A M A, 288,1987-$ 1993.

Alkrisat, M. (2011). The impact of workplace stress and stress of conscience on the moral distress of nurses in acute care settings. Ph.D. dissertation, Azusa Pacific University, California. Retrieved from Dissertations \& Theses: Full Text. (Publication No. AAT 3459283).

American Association of Colleges of Nursing. (AACN). (2008). Nurse faculty shortage fact sheet. Retrieved from http://www.aacn.nche.edu/Media/FactSheets/NursingShortage.htm.

AMN Healthcare. (2010). Survey of registered nurses: Job satisfaction and career plans. Retrieved from http://www.amnhealthcare.com/pdf/10_nursesurveyweb.pdf Benson, H. (1983). The relaxation response. Mind/Body medicine: How to use your mind for better health. Yonkers, NY: Consumer Reports Books.

Bormann, J., Becker, S., Gershwin, M., Kelly, A., Pada, L., Smith, T., \& Gifford, A. (2006). Relationship of frequent mantram repetition to emotional and spiritual wellbeing in healthcare workers. Journal of Continuing Education in Nursing, 37, 218-224.

Bormann, J., Oman D., Kemppainen, J., Becker, S., Gershwin, M., Kelly, A. (2006). Mantram repetition for stress management in veterans and employees: A critical incident study. 
Journal of Advanced Nursing, 53, 502-512.

Brown, K., \& Ryan, R. (2003). The benefits of being present: Mindfulness and its role in psychological wellbeing. Journal of Personality and Social Psychology, 84, 822-848.

Browning, L., Ryan, C., Greenberg, M., \& Rolniak, S. (2006). Effects of cognitive adaptation on expectation-burnout relationship among nurses. Journal of Behavioral Medicine, 29, 139150.

Buerhaus P. I., Staiger, D. O., \& Auerbach, D.I. (2008). The future of the nursing workforce in the United States: Data, trends, and implications. Boston, MA: Jones \& Bartlet.

Bureau of Labor Statistics (2011). Occupational outlook handbook, 2010-11 edition.

Retrieved from http://www.bls.gov/oco/ocos083.htm

Bureau of Labor Statistics (2012). Employee tenure in 2012. Retrieved from http://www.bls.gov/news.release/pdf/tenure.pdf.

Carlson, L. E., \& Brown, K. W. (2005). Validation of the mindful attention awareness scale in a cancer population. Journal of Psychosomatic Research, 58(1), 29-33.

Cannon, W. B. (1953). Bodily changes in pain, hunger, fear and rage. Boston, MA: Branford.

Cohen-Katz, J., Wiley, S. D., Capuano, T., Baker, D. M., \& Shapiro, S. (2004). The effects of mindfulness-based stress reduction on nurse stress and burnout. Holistic Nursing Practice, 18, 302-308.

Cohen-Katz, J., Wiley, S. D., Capuano, T., Baker, D. M., \& Shapiro, S. (2004). The effects of mindfulness-based stress reduction on nurse stress and burnout. Holistic nursing practice, 18, 302-308.

Cohen-Katz, J., Wiley, S., Capuano, T., Baker, D. M., Deitrick, L., \& Shapiro, S. (2005). 
The effects of mindfulness-based stress reduction on nurse stress and burnout: a qualitative and quantitative study, part III. Holistic Nursing Practice, 19(2), 78-86.

Cohen-Katz, J., Wiley, S. D., Capuano, T., Baker, D. M., Kimmel, S., \& Shapiro, S. (2005). The effects of mindfulness-based stress reduction on nurse stress and burnout, part II: A quantitative and qualitative study. Holistic nursing practice, 19, 26-35.

Department of Health and Human Services, Health Resources and Services Administration, Bureau of Health Professions. (2008) The registered nurse population: Findings from the 2008 national sample survey of registered nurses. Retrieved from http://bhpr.hrsa.gov/healthworkforce/msurvey2008.html Easwaran, E. (1993). Meditation: A simple eight-point program for translating spiritual ideals into daily life $\left(2^{\text {nd }}\right.$ ed.). Tomales, CA: Nilgiri Press.

Folkman, S., \& Lazarus, R. (1980). An analysis of coping in a middle-aged community sample. Journal of Health and Social Behaviour, 21, 219-239.

Freudenberger, H. J. (1974). Staff burn-out. J Social Issues, 30, 159-85.

Glasberg, A., Eriksson, S., Dahlqvist, V., Lindahl, E., Strandberg, G., Soderberg, A., Sorlie, V., \& Norberg, A. (2006). Development and initial validation of the stress of conscience questionnaire. Nursing Ethics 13, 633-648.

Günüșen, N., \& Üstün, B. (2010). An RCT of coping and support groups to reduce burnout among nurses. International Nursing Review, 57, 485-492. doi:10.1111/j.1466-7657.2010.00808.x

Heard, P. (2010). The relationship and effects of mindfulness on comfort, work satisfaction, and burnout among nurses who provide direct patient care. Ph.D. 
dissertation, The University of Southern Mississippi. Retrieved from Dissertations \& Theses: Full Text. (Publication No. AAT 3424877).

Institute of Medicine (2000). To err is human: Building a safer health system. Washington, DC: National Academy Press.

Institute of Medicine (2001). Crossing the quality chasm: A new health system for the $21^{s t}$ century. Washington, DC: National Academy Press.

Juthberg, C., Eriksson, S., Norberg, A., \& Sundin, K. (2007). Perceptions of conscience in relation to stress of conscience. Nursing Ethics, 14, 329-343. doi: $10.1177 / 0969733007075868$

Kabat-Zinn, J. (1994). Wherever you go there you are: Mindfulness meditation in everyday life. New York: Hyperion.

Kemper, K., Bulla, S., Krueger, D., Ott, M. J., McCool, J.,\& Gardiner, P. (2011). Nurses' experiences, expectations, and preferences for mind-body practices to reduce stress. BMC Complementary and Alternative Medicine. Retrieved from http://www.biomedcentral.com/1472-6882/11/26.

Komala, K., \& Ganesh, L. (2007). Individual spirituality at work and its relationship with job satisfaction and burnout: An exploratory study among healthcare professionals. The Business Review (Cambridge), 7, 124-129. doi: $10.1177 / 097168581001600203$.

Kutney-Lee, A., McHugh, M. D., Sloane, D. M., Cimiotti, J. P., Flynn, L., Neff, D. F., \& Aiken, L. H. (2009). Nursing: A key to patient satisfaction. Health Affairs, 28, 669-677. doi: 10.1377/hlthaff.28.4.w669.

Lazarus, R. S., \&S. Folkman (1984). Stress, appraisal, and coping. New York: Springer. 
Mackenzie, C. S., Poulin, P. A., \& Seidman-Carlson, R. (2006). A brief mindfulnessbased stress reduction intervention for nurses and nurse aides. Applied Nursing Research: $A N R, 19,105-109$. doi: 10.1016/j.apnr.2005.08.002

Marine A., Ruotsalainen. J., Serra C. \& Verbeek J. (2006). Preventing occupational stress in healthcare workers. Cochrane Database of Systematic Reviews. doi: 10.1002/14651858.CD002892.pub2.

Maslach, C., \& Jackson, S. (1981). The measurement of experienced burnout. Journal of Occupational Behaviour 2, 99-113.

Maslach, C., Jackson, S. E., \& Leiter, M. P. (1996). Maslach Burnout Inventory Manual (3rd ed.) Palo Alto, CA: Consulting Psychologists Press.

Maslach, C., Schaufeli, W. B., \& Leiter, M. P. (2001). Job burnout. Annual Review of Psychology, 52, 397-422.

McHugh, M.D., Kutney-Lee, A., Cimiotti, J. P., Sloane, D.M., \& Aiken, L. H. (2011). Nurses' widespread job dissatisfaction, burnout, and frustration with health benefits signal problems for patient care. Health Affairs, 30, 202-210; doi: $10.1377 /$ hlthaff. 2010.0100

McHugh, M. D., Aiken, L. H., Cooper, R. A., \& Miller, P. (2008). The U.S. presidential election and health care workforce policy. Policy, Politics \& Nursing Practice, 9, 6-14. doi: $10.1177 / 1527154408317852$.

National Institute for Occupational Safety and Health. (2008). Exposure to stress:

Occupational hazard in hospitals. Retrieved from http://www.cdc.gov/niosh/docs/2008-136/default.html.

National Institute for Occupational Safety and Health. (2011). Workplace safety and 
health topic: Healthcare workers. Retrieved from http://www.cdc.gov/niosh/topics/healthcare/.

Oman, D., Hedberg, J., \& Thoresen, C. E. (2006). Passage meditation reduces perceived stress in health professionals: A randomized, controlled trial. Journal of Consulting and Clinical Psychology, 74, 714-719. doi:10.1037/0022006X.74.4.714

Peterman, A. H., Fitchett, G., Brady, M.J., Hernandez, L., Cella, D. (2002). Measuring spiritual wellbeing in people with cancer: The functional assessment of chronic illness therapyspiritual wellbeing scale (FACIT-SP). Annals of Behavioral Medicine, 24, 49-58.

Polit, D., \& Beck, C. (2012). Nursing research: Principles and methods. Philadelphia: Lippincott Williams and Wilkins.

Poghosyan, L., Clarke, S. P., Finlayson, M., \& Aiken, L. H. (2010). Nurse burnout and quality of care: Cross-national investigation in six countries. Research in Nursing \& Health, 33, 288-298. doi:10.1186/1472-6882-11-26

Richards, T., Oman, D., Hedberg, J., Thoresen, C., \& Bowden, J. (2006). A qualitative examination of a spiritually-based intervention and self-management in the workplace. Nursing Science Quarterly, 19, 231-239.

Rowe, M. M. (1999). Teaching health-care providers coping: Results of a two-year study. Journal of Behavioral Medicine, 22, 511-527.

Shapiro, S. L., Astin, J. A., Bishop, S. R., \& Cordova, M. (2005). Mindfulness-based stress reduction for health care professionals: Results from a randomized trial. International Journal Of Stress Management, 12, 164-176. doi:10.1037/1072-5245.12.2.164

Schaufeli, W.B., Leiter, M.P., Maslach, C., \& Jackson, S.E. (1996). The MBI-general 
survey. In C. Maslach, S.E. Jackson, \& M.P Leiter (Eds.), Maslach Burnout Inventory_Manual_(3rd ed.), pp. 19-26. Palo Alto, CA: Consulting Psychologists Press.

Suzuki, E., Itomine, I., Kanoya, Y., Katsuki, T., Horii, S., \& Sato, C. (2006). Factors affecting rapid turnover of novice nurses in university hospitals. Journal of Occupational Health, 48, 49-61.

Vahey, D., Aiken, L., Sloane, D., Clarke, S., \& Vargas, D. (2004). Nurse burnout and patient satisfaction. Medical Care, 42, 57-66.

Yong, J., Kim, J., Park, J., Seo, I., \& Swinton, J. (2011). Effects of a spirituality training program on the spiritual and psychosocial wellbeing of hospital middle manager nurses in Korea. Journal of Continuing Education in Nursing, 42, 280-288. doi: $10.3928 / 00220124-20101201-04$ 
Appendix B

San Diego Veteran Affairs Healthcare Systems Research and Development

Committee Approval

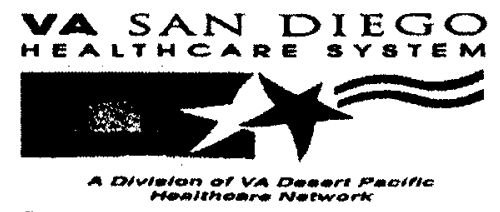

\section{Memorandum}

Date: March 15, 2012

From: ACOS, Research Service (151)

Subj: R\&D Committee Project Initial Approval [with stipulation]

To: Bormann, Jill, E. Ph.D., R.N. (111N-1)

Project Title: Efficacy of Internet Delivered Mantram Repetition Program (MRP) for Reducing Burnout in Healthcare Workers (HCWS)

[Application: 20120144; Project ID: 1167609; RDIS: \#pend; Protocol: 12-0252; VMRF ID:]

1. Your above referenced project has now been reviewed and approved by all applicable subcommittees as needed: Human Subjects (IRB), Animal Subjects (IACUC), Research Safety (SRS), Research Information Security (RIS), and Conflict of Interest (IRC).

2. Accordingly, your request to initiate the above research at the VA San Diego Healthcare System was reviewed and received final approval by the convened R\&D Committee on March 14, 2012, with the stipulation that within 30 days you address previous R\&D stipulations associated with Oct 12, 2011 continuing roview for project "Efficacy of Mantram Repotition on PTSD Symptoms in Veterans", RDIS 0012 (seo attachod). Fallure to addross $R \& D$ stipulations within $\mathbf{3 0}$ days may rosult in restrictions for this and other projects at the VA. Ploase contact me at gerherd.schulteis@va.gov or at VA ext. 7015, if you wish discuss further.

3. This approval is also made with the condition that only those personnel who have been appointed through VA Research Staffing Section and are current in all training requirements may participate. Your VA approved staff list is attached ( $N=$ not active). If you find discrepancies, please contact the Research Projects Section for further guidance and direction.

R\&D Committee Approval Period: March 14, 2012 - March 13, 2013

4. Please note that the R\&D Committee approval dates are usually not identical to other approval periods (e.g. IRB, IACUC). If your R\&D Committee project expiration of March 13, 2013, is more than 30-45 days removed from the expiration date of the IACUC and/or IRB protocol linked to your project, you are strongly encouraged to submit your R\&D Continuing Review documents simultaneously when you submit the appropriate continuing review documents to the IACUC or IRB. This will allow us to better synchronize future R\&D Committee reviews with subcommittee review dates, such that you as the investigator can focus on fewer renewal dates each year for this project.

5. Regardless of whether your project and protocol (IRB, IACUC) expiration dates are currently synchronized, we request that you submit R\&D continuing review documents at least six to eight weeks prior to the expiration date in order to maintain continual approval for this project. Any project without current a R\&D Committee approval will be restricted 
from any study activity as of the date of R\&D Committee expiration. You may contact the Research Projects Section at (858) 552-8585, Ext. 1157 for the appropriate renewal/continuation forms.

Gerhard Schulteis, PhD 


\begin{tabular}{|l|l|}
\hline PI & Bormann, Jill, E. Ph.D., R.N. \\
\hline RDIS Number & 0000 \\
\hline ProjectlD & 1167609 \\
\hline End Date & \\
\hline PDS Date & \\
\hline RDCC Status & Draf \\
\hline VARF ID & \\
\hline SRS Exempt & $\mathrm{Y}$ \\
\hline R\&D Status & Approved \\
\hline R\&D Explres & $3 / 13 / 2013$ \\
\hline Animal & $\mathrm{N}$ \\
\hline Human & $\mathrm{Y}$ \\
\hline Biological & $\mathrm{N}$ \\
\hline Chemical & $\mathrm{N}$ \\
\hline Radiation & $\mathrm{N}$ \\
\hline Physical & $\mathrm{N}$ \\
\hline Restriction & \\
\hline
\end{tabular}

Project Title: Efficacy of Intemet Delivered Mantram Repetition Program (MRP) for Reducing Bumout in Healthcare Workers (HCWS)

\begin{tabular}{|l|l|l|l|l|l|l|l|l|}
\hline Name & Active & Animal & Human & Bio & Chem & Rad & Phys & Restrict \\
\hline BORMANN, JILLE & $\mathrm{Y}$ & & $\mathrm{Y}$ & & & & & \\
\hline LEARY, SHERYLE. & $\mathrm{Y}$ & & $\mathrm{Y}$ & & & & & \\
\hline ANDREWS, TAYLOR RAAE & $\mathrm{Y}$ & & $\mathrm{Y}$ & & & & & \\
\hline HOLLINGER, GERI & $\mathrm{Y}$ & & $\mathrm{Y}$ & & & & & \\
\hline BECK, DANIELLEJ. & $\mathrm{Y}$ & & $\mathrm{Y}$ & & & & & \\
\hline
\end{tabular}




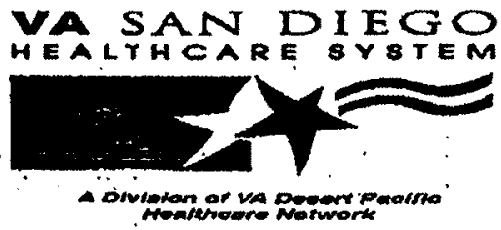

\section{Memorandum}

Date: October 13, 2011

From: ACOS, Research Service (151)

Subj: R\&D Committee Continuation Approval [with stipulation]

To: Bormann, Jill, E. Ph.D., R.N. (118)

Project Title: Efficacy of Mantram Repetition on PTSD Symptoms in Veterans [Application: 20111014; Project ID: 15586; RDIS: \#0012; Protocol: 08-1630; VMRF ID: 08251]

1. On October 12, 2011, the R\&D Committee conducted a continuing review of the above project and approved this study to continue for 365 days from this date, with the stipulation that the following document revisions be submitted to Laverne Estanol (x7005) within 30 days and prior to submission to the IRB:

a) Data destruction in current Records Control Schedule does not permit destruction and date of destruction of sensitive data or of copies of non-sensitive research records. Remove text that indlcate "... will be destroyed no later than December 30, 2014 under the direction of Jill Bormann, Pl." in Sections 14 of the Research Plan.

b) Ensure the list of research personnel are current in these documents: IRB Standard Application Face Sheet (section 7), Research Plan (personnel section), and the VA Staff Lst. Key personnel and personnel that will be engaged (direct Interaction with subjects and/or access to subject identifiable data) in the protocol should be included. Those Involved in the VA component should have completed the VA research training and credentialling (WOC).

This approval is also made with the condition that only those personnel who have been appointed through VA Research Staffing Section and are cument in all training requirements may participate. Your VA approved staff list is attached. If you find discrepancies, please contact the Research Projects Section for further guidance and direction.

R\&D Committee Approval Period: October 12, 2011 - October 11, 2012

2. R\&D Committee approval of this project will explre on October 11, 2012. Continuing review and approval by the R\&D Committee must be completed by this date or the research activities must cease until (and if) a new R\&D project and submission has been reviewed and approved. There can be no exceptions. Remember to submit your continuation requests 8 weeks prior to this expiration date.

3. Please note that Subcommittee approvals must remain current throughout the R\&D approval project period. 
4. You may contact the Research Projects Section at (858) 552-8585, Ext 1157 for the appropriate forms.

\section{Gerhard Schulteis, PhD}


Appendix C

Instrument Permissions

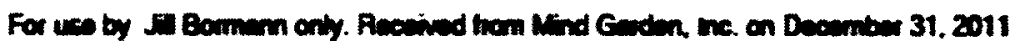

Permiesion lor dill Bormam to reproduce 150 copies within one yeer of December 31, 2011

\title{
Maslach Burnout Inventory \\ Instruments and Scoring Guides
}

Forms: General, Human Services, 8 Educators

\author{
Chrietina Mastech \\ Susen E Jackacon \\ Miched P. Leiter \\ Wimer B. Scheufeli \\ Richard L. Schueb
}

\author{
Publiahed by Mind Gerden \\ infoemindgarden.com \\ mm.mindgarden.com
}

\section{Important Note To Licensee}

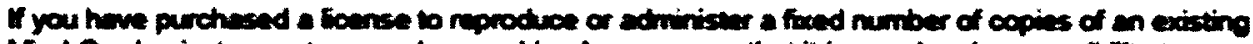

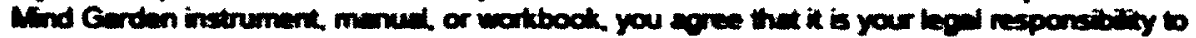

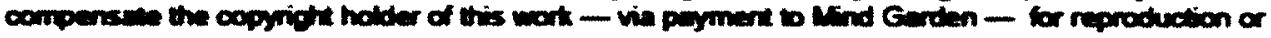

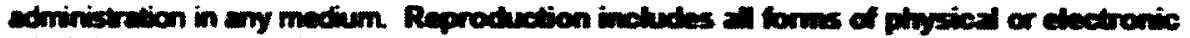

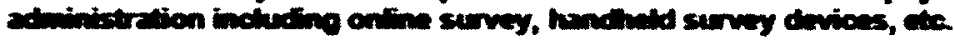

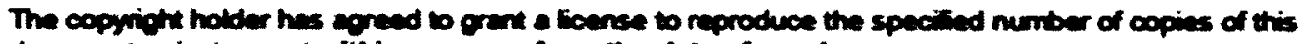

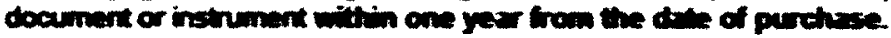

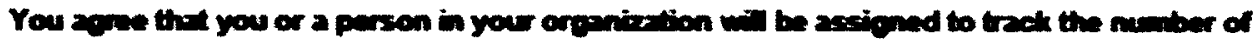

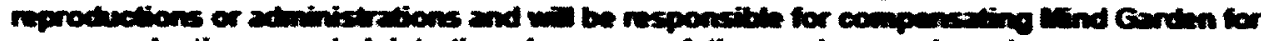
any reproductions or administretions in eweess of the mumber purehreed.

Coppriete 1900 by CPP. he. All rotits resemed in all moduma.

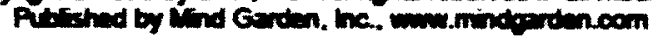


Dear Sheryl Leary

You have our permission to use our questionnaire Stress of Conscience (SCQ) in your dissertation study. We are interested in your results and would like to read those when they are ready. So please, keep us informed. Good luck with your work!

Yours sincerely, Gunilla Strandberg, professor at the Department of Nursing, Umea University, Sweden and project manager for 'The stress och conscience study'.

Från: Christina Juthberg

Skickat: den 26 mars 2012 10:48

Till: Gunilla Strandberg

Ämne: VB: Stress of Conscience

Gunilla, vad tror du om detta? /C.

Från: Sheryl Leary [mailto:sherylleary@gmail.com]

Skickat: den 23 mars 2012 19:31

Till: Christina Juthberg

Ämne: Fwd: Stress of Conscience

Hello,

I am trying to reach Dr Glasberg however the email is "returned to sender". I note you have authored with her, so could you help me?

Thank you, Sheryl Leary

-.-- Forwarded message

From: Sheryl Leary

<sherylleary@gmail.com<mailto:sherylleary@gmail.com>>

Date: Fri, Mar 23, 2012 at 11:29 AM

Subject: Stress of Conscience

To: ann-louise.glasberg@nurs.umu.se<mailto:ann- 
louise.glasberg@nurs.umu.se>

Dear Dr. Glasberg,

I am a doctoral student at the University of San Diego in California and found your information while conducting a literature search. My dissertation topic is the relationship of a Mantram Repetition Program on healthcare worker's burnout. The program teaches how to repeat a Mantram, a sacred or spiritual word or phrase, silently and intermittently throughout the day to train attention and redirect unwanted thoughts. It also teaches tools of slowing down and one-pointed attention as a means of emotional self-regulation.

May I have permission to use your Stress of Conscience (SCQ) in my dissertation study?

Thank you very much for your time.

Respectfully, Sheryl Leary 